\title{
Nanoparticle Pre-Conditioning for Enhanced Thermal Therapies in Cancer
}

\author{
Mithun M. Shenoi ${ }^{1}$, Neha B. Shah ${ }^{1}$, Robert J. Griffin ${ }^{5}$, Gregory M. Vercellotti ${ }^{3}$, and John C. \\ Bischof ${ }^{1,2,4, *}$ \\ ${ }^{1}$ Department of Biomedical Engineering, University of Minnesota, Minneapolis, Minnesota 55455, \\ USA \\ ${ }^{2}$ Department of Mechanical Engineering, University of Minnesota, Minneapolis, Minnesota 55455, \\ USA \\ ${ }^{3}$ Department of Medicine, University of Minnesota, Minneapolis, Minnesota 55455, USA \\ ${ }^{4}$ Department of Urological Surgery, University of Minnesota, Minneapolis, Minnesota 55455, USA \\ ${ }^{5}$ Department of Radiation Oncology, University of Arkansas for Medical Sciences, Little Rock, \\ Arkansas 72205, USA
}

\begin{abstract}
Nanoparticles show tremendous promise in the safe and effective delivery of molecular adjuvants to enhance local cancer therapy. One important form of local cancer treatment that suffers from local recurrence and distant metastases is thermal therapy. Here we review a new concept involving the use of nanoparticle delivered adjuvants to "pre-condition" or alter the vascular and immunological biology of the tumor to enhance its susceptibility to thermal therapy. To this end, a number of opportunities to combine nanoparticles with vascular and immunologically active agents are reviewed. One specific example of pre-conditioning involves a gold nanoparticle tagged with a vascular targeting agent (i.e. TNF- $\alpha$ ). This nanoparticle embodiment demonstrates preconditioning through a dramatic reduction in tumor blood flow and induction of vascular damage which recruits a strong and sustained inflammatory infiltrate in the tumor. The ability of this nanoparticle pre-conditioning to enhance subsequent heat or cold thermal therapy in a variety of tumor models is reviewed. Finally, the potential for future clinical imaging to judge the extent of pre-conditioning and thus the optimal timing and extent of combinatorial thermal therapy is discussed.
\end{abstract}

\section{Keywords}

Nanoparticle pre-conditioning; colloidal gold; TNF- $\alpha$; thermal therapy; hyperthermia; cryosurgery; cryotherapy; cancer

\section{Introduction}

Nanotechnology holds tremendous promise for the treatment of cancer. Recent work has focused on the unique potential of nanotechnology to improve drug delivery, imaging

\footnotetext{
*Corresponding Author: John C. Bischof, Professor, Department of Mechanical Engineering, University of Minnesota, 111 Church Street SE, Minneapolis, MN 55455, USA, Phone: +1-612-625-5513, Fax: +1-612-625-4344, bischof@umn.edu.

Financial Disclosure

The authors declare no competing financial interests.
} 
contrast, and heating of tumors over traditional methods in cancer treatment $[1,2]$. In some cases, nanoparticles have multifunctional properties or potential for therapy and diagnostics that has led to a new field entitled "theranostics" [3]. There are also increasing opportunities for combinatorial treatment of cancer with nanoparticles [4]. Several classes of nanoparticles, including liposomes, magnetic and metallic, are now in clinical trials for cancer thermal therapy (Table 1). This report explores the opportunities for nanoparticle based thermal therapy enhancement. Many approaches using nanotechnology are based on the delivery and acute activation of particles to tumors to induce cell death via drug release or thermal cytotoxicity. The work we will review here is distinct in that we refer specifically to a relatively unexplored and exciting opportunity to use nanoparticles to alter the vascular and immunological biology of the tumor (pre-conditioning) to augment the antitumor effects of subsequently applied thermal therapy.

About 1.5 million cases of cancer were projected to be diagnosed in the US in 2009 [5]. The NIH estimates overall costs of cancer in 2008 at \$228.1 billion with $\$ 93.2$ billion for direct medical costs (all health expenditures) [5]. Of these, the most prevalent are prostate, breast, colorectal (with metastasis to liver) and lung cancer with 146,000-192,000 new cases each expected in 2009 . The primary treatments for these diseases have traditionally been surgical resection, chemotherapy and radiation. However, other approaches are needed for patients who are poor surgical candidates and for those whose primary treatment has failed. This has spurred the growth of alternative approaches including probe based thermal therapies, or thermal "ablative" technologies for cancer over the last 20+ years [6].

Thermal therapies include: cryosurgery (freezing), radiofrequency ablation (RFA), microwave, laser, magnetic fluid hyperthermia and high intensity focused ultrasound (HIFU) [6] (Table 2). The advantages of thermal therapies include: focal, repeatable, and minimally or non-invasive application with the ability to use image guidance as recently reviewed in a clinically based text on the subject [6]. Unfortunately, while thermal therapies can destroy tissue, a major clinical limitation to their increased use is local recurrence of disease $[7,8]$. Researchers in the field have argued that this is generally due to an inadequate understanding and control of the thermal dose, i.e. the necessary temperature and time of exposure needed to ensure killing of all tumor cells $[9,10]$. One way to address this is by selectively and controllably reducing the thermal dose required for cytotoxicity between the diseased tissue and normal tissue using combinatorial approaches involving nanoparticles.

\section{Nanoparticles in Thermal Therapies}

In thermal therapies for cancer, nanoparticles have been investigated mainly for novel methods of in situ delivery of thermal energy to tumors, as recently reviewed [11]. These approaches utilize the unique properties of nanoparticles inherent to their size and composition such as optical and dielectric properties, magnetic susceptibility, thermal or electrical conductivity. The techniques are, in general, minimally invasive and aim to achieve superior localized heating of the entire tumor mass while sparing surrounding normal tissues. For instance, magnetic fluid hyperthermia aims to heat tissue in an alternating electromagnetic field using nanoparticles of specific size and magnetic susceptibility. This was originally pioneered by Gilchrist in the 1950s with iron oxide [12], but remains an approach of interest as evidenced by clinical trials in Europe for treatment of glioblastoma multiforme and prostate tumors (See Magnetic Fluid Hyperthermia, Table 2) $[13,14]$. More recently, photothermal therapy is a growing field where laser light is used to heat nanoparticles (i.e. spherical, rod, and shell particles) with the intention to selectively destroy cells loaded with nanoparticles. Several novel nanoparticle formulations such as gold nanorods, gold nanocages, carbon nantubes, etc. are being tested in vitro and in vivo to target tumor cells with the goal of achieving photothermal destruction [15-18]. Von 
Maltzahn et al. have recently shown that a single injection of polyethylene glycol coated gold nanorods enabled complete photothermal destruction of human xenograft tumors in mice [19]. In a separate study, Zhou et al. have shown the efficacy of copper sulfide nanoparticles in simultaneous in vivo imaging and photothermal ablation therapy [20]. The real potential of photothermal therapy using nanoparticles is evidenced by the fact that plasmonically active nanoshells are currently in clinical trials in the USA using this technology (See Laser, Table 2) [21]. In addition, recent work with radiofrequency Joule heating of gold nanoparticles at $13.56 \mathrm{MHz}$ seems promising for heating cancer cells at nanoparticle concentrations far below that necessary for effective magnetic fluid hyperthermia; although exceptionally high powered fields (i.e. $600 \mathrm{~W}$ generator) are needed [22]. It is worth noting here that, similar to other nanoparticle-based therapies, the success of these approaches is highly-dependent on tumor-specific localization of the nanoparticle using a targeted approach [23].

A separate multi-modal approach using nanoparticles in thermal therapies involves delivery of chemotherapeutics to enhance direct cell injury mechanisms. Traditional combinatorial approaches involving chemotherapy or radiation therapy have been utilized in the past in conjunction with hyperthermia [24, 25]. Mild hyperthermia impacts tumor physiology by increasing tumor perfusion and vascular permeability [26]. These effects along with perforation of tumor blood vessel walls, microconvection in the tumor interstitium, and perforation of the cancer cell membrane induced by mild hyperthermia are all conducive to improved drug delivery to tumor stromal and parenchymal compartments [27]. Preclinical work on this approach has shown considerable promise in synergistic destruction of tumor cells, however, the data from preliminary clinical trials while mostly positive, have varied in demonstrating synergy [28-32]. With advances in nanotechnology research, a natural extension of this approach is to package chemotherapeutics in nanoparticle delivery systems for use in combination with thermal therapies. To date the most successful of these strategies is based on liposomal technologies. New clinical trials that involve liposomes with thermal approaches are emerging rapidly. Perhaps the most exciting extension of this concept is the use of a thermally-sensitive liposome that encapsulates anti-cancer agents and is released locally and selectively where the heat is applied. Ponce et al. report on the conception, development and preclinical studies demonstrating increased efficacy using these nanoparticles (liposomes) loaded with doxorubicin in the setting of hyperthermia for cancer therapy [33]. Goldberg et al. report the first preclinical and clinical use of these nanoparticles in conjunction with RFA [34, 35]. In their pilot clinical study on patients with focal hepatic tumors, they show that a single intravenous dose of liposomal doxorubicin (Doxil) administered 24 hours before RFA of the tumors resulted in increased tissue damage at the site of thermal injury compared to RFA alone [34]. These research efforts have resulted in the commercialization of the nanoparticle, ThermoDox ${ }^{\mathrm{TM}}$, and initiation of several clinical trials of combinatorial therapy of ThermoDox ${ }^{\mathrm{TM}}$ with hyperthermia or RFA [201]. Emerging work in this area includes thermally-sensitive nanoparticles that release genes (i.e. gene therapy) during hyperthermia [36], or freeze sensitive nanoparticles that release drug locally during cryosurgery [37]. These advancements show the potential clinical utility of nanoparticles to enhance direct destruction of tumor cells with thermal therapy. A new but related concept using nanoparticles functionalized with bioactive ligands to "pre-condition" vascular and immunological mechanisms of tumor destruction prior to thermal therapies (Figure 1) has also shown significant potential to enhance outcomes as reviewed below.

\section{Nanoparticle Pre-conditioning of Tumors for Thermal Therapy}

We define "pre-conditioning" as the use of a bioactive agent (e.g. TNF- $\alpha$, arsenic trioxide, interleukins, etc.) to modify the vascular and/or immunological components of the tumor 
microenvironment so as to make the tumor tissue more susceptible to a secondary treatment such as thermal therapy. Pre-conditioning of the tumor with bio-conjugated nanoparticles requires an understanding of the in vivo mechanisms of thermal injury and the wound healing response that follows. The tumor microenvironment is a complex milieu resultant of the competing interactions between several pro- and anti-tumorigenic components (cytokines, endothelial cells, inflammatory cells, fibroblasts, extracellular matrix elements) [38]. The goal of pre-conditioning is to shift the balance of these interactions in the antitumorigenic direction so as to enhance the outcome of thermal therapies (i.e. increased and controlled tumor cell kill, decreased local recurrence). Several components of the tumor microenvironment are amenable to pre-conditioning by drugs already in preclinical or clinical trials (Table 3).

\section{Selection of Pre-conditioning Agent and Nanoparticle Design}

Although a large number and wide variety of potential pre-conditioning agents are available (Table 3), the biomolecule of interest in our recent studies, TNF- $\alpha$, is an ideal preconditioning agent due to its well-established mechanism of action against the tumor vasculature, potential for sensitizing tumor cells to thermal injury, potential for eliciting an antitumor immune response, and documented clinical success in solid tumor therapy in native and nanoparticle form (although currently limited in scope). In vitro studies conducted by our group have shown that pre-treatment with native TNF- $\alpha$ sensitizes various tumor cell lines to thermal (heat and cold) injury [39-41]; however, the effect is more pronounced in microvascular endothelial cells. This suggests that even though direct cytotoxicity of tumor cells may be enhanced following thermal therapy the primary mechanism of pre-conditioning plays out within the tumor vasculature. CYT-6091, a polyethylene glycol (PEG) coated gold nanoparticle tagged with tumor necrosis factor alpha (TNF- $\alpha$ ), has been explored by our group to deliver TNF- $\alpha$ to the tumor vasculature and precondition the tumor microenvironment for enhancement of thermal (heat and cold) therapies. CYT-6091 has already completed a Phase I clinical trial as a standalone anticancer therapeutic $[42,43]$. The significant findings of the trial include lack of dose limiting toxicities or drug related serious adverse events, even at a 3-fold higher dose of 600 $\mu \mathrm{g}$ TNF- $\alpha / \mathrm{m}^{2}$ than the maximum tolerated dose of native TNF- $\alpha$ [43]. In addition, an absence of a systemic hypotensive response was observed, a major limiting factor that has restricted the use of native TNF- $\alpha$ in the clinical setting to isolated limb perfusion treatment of high-grade sarcomas and melanomas [44]. The base rationale behind attaching the cytokine to a nanoparticle (CYT-6091) is to reduce systemic toxicity and improve the localization of TNF- $\alpha$ to the tumor tissue. In several preclinical tumor models, we have shown that a single systemic injection of CYT-6091 4 hours prior to thermal therapy results in enhanced therapeutic outcome similar to that of previous preclinical work [45], yet with little to no overt toxicity. The toxicity profile of CYT-6091 may be further improved by the addition of a tumor targeting moiety to the gold nanoparticle such as antibodies, peptides or aptamers. This approach, especially using antibodies to target tumor cell receptors, has been widely tested in various cancers and would reduce the exposure of healthy tissues to TNF- $\alpha$ thereby improving its toxicity profile [23]. This nanoparticle design should allow entry in the tumor via the enhanced permeability and retention (EPR) effect and binding onto the tumor cells. A potential caveat of using nanoparticles to pre-condition tumors for enhanced thermal therapies is the ability of the nanoparticles to directly modify the thermal properties of tumor tissue. This is an area of intense research in the nanotechnology community but only a limited number of studies have been conducted to investigate this behaviour of nanoparticles in biological tissues. In one study, Liu and colleagues conducted experiments that suggested an increase in thermal conductivity of ex vivo tissues when injected locally with a large amount of iron oxide nanoparticles (estimated at 5\% local particle volume fraction) [46]. In the case of gold nanoparticles, a recent study by Shalkevich et al showed 
no significant increase in the thermal conductivity of gold nanoparticles suspended in water even at particle volume fraction of $0.11 \%$ [47]. These results indicate that incredibly high volume fractions of nanoparticles are required within tumors to affect its thermal properties. Our biodistribution results for CYT-6091 yield tumor particle volume fractions on the order of $10^{-5} \%$ when injected intravenously [48]. Similar particle volume fractions on the order of $10^{-8}-10^{-5} \%$ were obtained in another study using $20-100 \mathrm{~nm}$ diameter neutral PEG coated gold nanoparticles [49]. Thus, we can safely assume that changes in the thermal properties of tumors by nanoparticles do not contribute to the thermal sensitization obtained by the preconditioning mechanisms described below.

\section{Pharmacokinetics and Biodistribution}

The use of nanoparticles for pre-conditioning the tumor is dependent on delivery of the molecular payload to the tumor site. A limited number of studies have been conducted to determine the pharmacokinetics and biodistribution of gold nanoparticles in vivo. These studies usually look at the effect of size, shape, charge, coating and targeting moiety on the biodistribution of nanoparticles. De Jong et al. studied the effect of size on the biodistribution of gold nanoparticles in naïve rats at 24 hours after intravenous injection [50]. Their results showed that the highest accumulation of nanoparticles occurred in the liver with the $10 \mathrm{~nm}$ nanoparticles showing widespread accumulation in various organs. Another study of gold based core-shell particles showed that the maximum tumor accumulation occurs at 24 hours whereas the overall highest accumulation occurs in the spleen (up to 24 days) [51]. More recently, Perrault et al. conducted an elaborate study of the effect of particle size (20-100 nm) and surface chemistry (amount of PEG) on the pharmacokinetics and biodistribution of PEG coated gold nanoparticles [49]. In that study, athymic nude mice implanted with human breast cancer xenograft tumors were used to systematically examine how particle design can be optimized towards efficient tumor targeting. The authors of the study note that two desirable properties of the nanoparticles for tumor targeting - small hydrodynamic diameter and long half-lives - appear to converge when particles below $50 \mathrm{~nm}$ are protected with a PEG layer of moderate molecular weight (MW $5 \mathrm{kDa}$ ). To support this claim, they present results on the permeation of different sized PEG coated gold nanoparticles through the tumor interstitial space with the smallest diameter $(20 \mathrm{~nm})$ particles migrating furthest away from the tumor vasculature (Figure 2B). These and a host of other studies, mainly using liposomal nanoparticles, have led to three major insights into in vivo biodistribution of nano-sized agents: 1) smaller particles (20$200 \mathrm{~nm}$ ) are readily taken up in the tumor due to leaky vasculature (EPR effect); 2) surface modification with hydrophilic polymers (PEG) can reduce uptake by reticuloendothelial (RES) organs (such as liver and spleen); 3) attachment of the targeting moieties on the particle surface results in selective (but not exclusive) uptake by the target organs or tumors [52]. These insights were incorporated in the development of CYT-6091 (a $30 \mathrm{~nm}$ diameter colloidal gold nanoparticle coated with PEG and tagged with TNF- $\alpha$ ) and resulted in promising biodistribution results obtained in preclinical studies [53].

In our recent studies, a certain degree of tumor targeting of CYT-6091 was verified through pharmacokinetic and biodistribution studies (Figure 2) [48]. A single intravenous injection of CYT-6091 resulted in preferential accumulation of bioactive TNF- $\alpha$ in human prostate xenograft tumors (LNCaP Pro 5) grown in the hindlimb of nude mice within 4 hours as compared to the liver and spleen, the major organs of the reticuloendothelial system that play a vital role in nanoparticle clearance. We also detected that the presence of TNF- $\alpha$ influenced the biodistribution of CYT-6091 by extending the blood circulation time of the gold nanoparticle with reduced uptake in the liver 4 hours after injection [48]. Importantly, loading of the nanoparticle in tumor tissue was also significantly increased by the presence of TNF- $\alpha$ on the surface of the injected particles (Figure 2A, 2C). These findings are in line 
with previously published data [53]. We have also conducted in vitro studies using confocal Raman microscopy to non-invasively image the uptake of CYT-6091 by LNCaP tumor cells revealing unique spectroscopic features corresponding to the intracellular localization of GNPs over 2 to 24 hours at the membrane, cytoplasm or nucleus (Figure 2D) [54]. These results established that targeted delivery of TNF- $\alpha$ to tumors by CYT-6091 was possible with limited adverse side effects while also setting the timeframe over which preconditioning of the tumor may occur prior to thermal therapy. We have focused much of our recent attention on this particle to develop improved combined treatment strategies since it encompasses feature that we hypothesized would be ideal for sensitization of tumors to subsequent thermal exposures and is progressing in clinical testing (Phase II). There is therefore significant potential to translate the pre-conditioning approach to the clinic in the relatively near future.

\section{Vascular Pre-conditioning by TNF- $\alpha$ or other agents}

Systemic delivery of TNF- $\alpha$ through the bloodstream likely leads to its interaction with TNF receptor 1 (TNFR-1) on the luminal side of tumor-associated endothelial cells, setting off a cascade of intracellular molecular interactions that are grouped into two major pathways: $\mathrm{NF \kappa B}$-activated pro-inflammatory pathway and caspase-mediated apoptotic pathway. In vivo inhibition studies have revealed that the $\mathrm{NF \kappa B}$-activated pro-inflammatory pathway in endothelial cells is critical for pre-conditioning the tumor with native TNF- $\alpha$ to enhance thermal therapy [39]. These pro-inflammatory changes result from de novo gene transcription and translation of proteins mediated by NFKB and require around 2 to 6 hours to reach peak response [55]; thus, setting the 4 hour timeframe to obtain effective preconditioning. The pro-inflammatory changes induced by TNF- $\alpha$ include vascular hyperpermeability, increased expression of cell adhesion molecules and chemokines (ICAM-1, VCAM-1, E-selectin, P-selectin, CXCL8), recruitment of leukocytes (neutrophils, monocytes), leukocyte-mediated endothelial cell injury, increased synthesis of tissue factor, increased procoagulant activity and decreased anticoagulant activity (Figure 3A-B, 4) [44, $55,56]$. Consistent with these results, Farma et al. measured the rate of interstitial accumulation of an intravenously administered fluorescent marker in TNF- $\alpha$ sensitive and resistant tumors and showed that CYT-6091 induced a selective and rapid alteration of permeability of the tumor vasculature that was tissue factor dependent [57].

Such vascular changes may also be elicited by other potential pre-conditioning agents (Table 3). For example, vascular destructive agents (VDAs) target endothelial cells and pericytes of established tumor vasculature to cause complete tumor vascular shutdown. We have demonstrated that the FDA-approved anti-leukemic agent Arsenic Trioxide has such effects on the microvasculature of solid tumors [58-61]. This likely occurs due to severe oxidative stress and cell death in the vasculature upon exposure to arsenic which leads to vascular stasis and sensitivity to thermal therapy. One subset of VDAs, tubulin-binding agents (e.g. CA4P), disrupt endothelial cytoskeleton or interfere with cell-to-cell contact leading to increased vascular permeability, exposure of basement membrane and induction of the coagulation cascade resulting in thrombosis. Another subset of VDAs, flavonoids (e.g. DMXAA), have a more complex mechanism of action involving DNA damage to endothelial cells inducing apoptosis and upregulation of NFKB pathways similar to the purported mechanism of action of CYT-6091 leading to tumor vascular shutdown [62]. These VDAs are already in phase I and II clinical trials for cancer therapy and represent ideal first-line candidates for tagging on to nanoparticles for pre-conditioning tumors prior to thermal therapies $[62,63]$. Other well-studied molecules/drugs such as vasoactive agents (bradykinin, prostaglandins, leukotrienes, etc.) that induce vascular permeability or procoagulant molecules (thromboxane, tPA, etc.) that induce vasoconstriction and thrombosis could also be tested as pre-conditioning agents when tagged on to nanoparticles for selective 
and non-toxic delivery to tumor vasculature (See Table 3). Many of these agents do not exhibit their activity on the tumor vasculature alone. Instead, immunological reactions to the cell death occurring in the tumor (such as leukocyte recruitment due to the damage response by the vasculature) often appears to be an intrinsic component of their mechanisms of action. Systemically administered native TNF- $\alpha$ or CYT-6091 may activate circulating blood cells such as neutrophils which would increase their recruitment to the tumor vasculature [64]. These pro-inflammatory changes in the host and the tumor act synergistically with vascular (coagulation and thrombosis) responses after thermal therapyinduced tissue damage to contribute to the enhanced tumor destruction observed after these combined treatments.

\section{Immunological Pre-conditioning}

Ongoing research in our group has implicated that neutrophil-endothelial cell interaction following combined nanoparticle and thermal therapy leads to endothelial cell apoptosis that further enhances the ultimate antitumor effects of vascular pre-conditioning [65]. However, it is unclear if the role of neutrophils in tumor destruction ends here. There is evidence to suggest that neutrophils play a larger role in causing direct tumor cell death as well as in modulating the downstream antitumor adaptive immune response [66]. The dual nature of immune cells in relation to the tumor microenvironment is well-recognized and studied in macrophages and $\mathrm{T}$ lymphocytes $[67,68]$. Thus, there exists an opportunity for immunological pre-conditioning of the tumor which could involve polarization of tumorassociated macrophages to enhance tumor kill or by promotion of cytotoxic $\mathrm{T}$ lymphocyte mediated tumor destruction. This type of pre-conditioning could act in concert with vascular pre-conditioning mechanisms as may be the case with CYT-6091. TNF- $\alpha$ is known to promote antitumor immune responses and current research in our group is geared towards understanding the role of TNF- $\alpha$ and CYT-6091 in modulating the adaptive immune response and long term wound involution following thermal therapy [69]. Several other immune modulating biomolecules (Table 3 ) have shown potential to act as pre-conditioning agents as well. For example, a variety of cytokines (e.g. IL-2, IL-12, IFN- $\alpha$ in addition to TNF- $\alpha$ ) are in clinical trials as antitumor therapeutics especially in combination with chemotherapy (Table 3).

Anti-CTLA4 antibodies are another particularly exciting prospect as pre-conditioning agents because they have been extensively researched and are also already in clinical trials though not in combination with thermal therapies. These antibodies are known to successfully inhibit the immunosuppressive environment of tumors to elicit an effective antitumor immune response however their clinical use is limited by autoimmunity side effects due to the high systemic dose required [70]. To overcome this limitation, Lei et al. have tested a nanoparticle system loaded with anti-CTLA4 antibodies in a preclinical tumor model showing increased antitumor activity with decreased toxicity compared to native antibodies [71]. Other immune modulating agents such as TGF- $\beta$ inhibitors and toll-like receptor (TLR) agonists are also gaining immense clinical interest as antitumor therapeutics (Table 3). By taking into account the mechanisms of thermal injury (heat and cold) in their selection, a wide variety of vascular and immunological pre-conditioning agents with near term potential wold be expected to have great potential to be combined with nanotechnology to enhance thermal therapies in cancer and avoid the typical side effects encountered with each type of agent when used systemically on their own.

\section{Mechanisms of Thermal Injury}

The vast amount of literature on thermal therapies differentiates between three forms of thermal (heat and cold) injury in tumor tissues: direct cell injury, vascular injury and immunological injury [72-74]. In cold-based therapies (i.e. cryosurgery), the tissue is frozen 
usually to a cryogenic (i.e. $<-40{ }^{\circ} \mathrm{C}$ ) temperature. In this process, damage to cells typically occurs by a phase change event of intracellular or extracellular water (liquid to solid) causing either extreme dehydration or intracellular ice formation [72]. This can in turn lead to biochemical events such as protein denaturation or peroxidation of lipids that terminate in necrosis or apoptosis of the cells $[72,74]$. In a distinct but related manner, heating of cells yields phase change within the macromolecules (protein, DNA, lipids) of cells themselves. However, most of the research evidence points to protein denaturation as the rate limiting step in direct cell injury due to heating [75]. If these events are sub-lethal there is usually heat shock response that can interact with the proteins and lipids and keep the cell alive, however, once the injury is too severe cell death occurs again by necrotic or apoptotic mechanisms [75]. In the case of both heat and cold direct cell injury, the end result is membrane destabilization and hyperpermeability [72, 73]. Pre-conditioning agents that decrease the threshold for hyperpermeability of cell membranes could thus improve nanoparticle uptake and facilitate delivery of cytotoxic drugs via nanoparticles into tumor cells. Microenvironmental factors such as tumor blood flow, $\mathrm{pH}$ and oxygenation are known to affect the thermosensitivity of tumor cells and thus present an opportunity for modulation by pre-conditioning agents to increase the thermosensitivity of tumor cells [73]. For example, blood flow acts as a heat sink and source in hyperthermic and cryotherapy respectively hindering the attainment of lethal end temperatures within the tumor tissue during thermal therapy. Direct cell injury is an important mechanism of thermal injury; however, in vivo it is supplemented by vascular injury mechanisms that extend the thermal damage. During cold-based therapies, microvascular shutdown usually occurs at $-20{ }^{\circ} \mathrm{C}$ after moderate cooling and thawing rates in a variety of tissues, although this can occur at slightly higher temperatures in tumors [72]. Similarly, hyperthermia even at mild supraphysiological temperatures can cause microvascular dysfunction and shutdown in tumor tissues [26]. One possible difference between heat and cold injury is the amount of tumor tissue that undergoes reperfusion after the intial thermal insult. Blood flow, which will cease during the freezing event, is usually re-established after thaw. However, after thermal therapy only the volume of tumor tissue exposed to lower hyperthermic temperatures $\left(<50^{\circ} \mathrm{C}\right)$ can undergo reperfusion due to the central part of the thermal lesion exposed to higher temperatures being coagulated or thermally fixed [76]. This mechanistic difference may affect ischemia-reperfusion injury differentially in thermal injury by heat versus cold based therapies. It is now well-established that vascular injury progresses beyond the initial thermal insult (both heat and cold) and typically peaks at day 3 following thermal therapy $[72,73]$. Tumor endothelial cell damage is the hallmark of vascular injury leading to increased vascular leakage, vessel wall adhesiveness and coagulation and thrombotic events within the tumor vasculature [73]. This progressive cessation of blood flow leads to ischemia within tumor tissue and necrosis of tumor cells. This mechanism of thermal injury is exploited in the use of CYT-6091 as a pre-conditioning agent and serves as the rationale for exploring other vascular pre-conditioning agents (Table 3) for use in combination with thermal therapies. The progression of vascular injury in the thermal lesion is also accompanied by recruitment of inflammatory cells (neutrophils) that could be responsible for the progressive nature of vascular damage or may be directly exerting cytotoxic effects on remnant viable tumor cells within the thermal lesion $[66,77,78]$.

The final, relatively poorly understood, mechanism of immunological stimulation/injury in thermal therapies is based on the premise that thermal injury activates a host-mediated antitumor immune response. Sabel provides a thorough review on the conflicting set of preclinical studies examining the immune response to cryosurgery [79]. The immune response following hyperthermia is also actively being studied [80]. However, there is still a lack of clear understanding of the exact mechanisms of the immune response following thermal therapies partly due to distinct differences observed when time/temperature history and local versus whole body heating are considered. There is evidence to suggest that 
necrotic cells releasing 'danger signals' are more efficient at inducing an immune response than apoptotic cells [81]. Thus we may hypothesize that thermal therapies resulting in an increased fraction of necrotic versus apoptotic cells would be more amenable to immunological injury. It is also conceivable that certain thermal therapies may induce a greater release of 'danger signals' and thus a stronger antitumor immune response from the host which could be yet another way to differentiate between heat and cold based therapies. For example, the coagulative and thermally fixed zone formed in high temperature therapies could prevent the release and exposure of danger signals to the host immune cells indicating possibly leading to a variable immune response compared to cold based therapies. Various studies have demonstrated synergistic antitumor effects when combining immunotherapy and thermal therapies (both heat and cold) (Table 3). In general, there is much still to be learned about the role of inhibitory elements of the immune system and the induction of effective antitumor immunity by thermal or other methods. It seems imperative that the immune portion of the antitumor effect of vascular damaging nanoparticle and thermal therapy delivery strategies must be accounted for by using immunocompetent models as much as possible or in addition to xenograft models.

We have demonstrated numerous positive tumor responses in our models with nanoparticle pre-conditioning for improved hyperthermia and cryosurgery in both immunocompetent and immunocompromised models (Table 4).

\section{Nanoparticle Enhanced Hyperthermia}

The first demonstration of nanoparticle pre-conditioning enhancement of tumor thermal therapy was conducted by Visaria et al. [41]. In this work, SCK hindlimb tumors grown in $\mathrm{A} / \mathrm{J}$ mice and FSaII hindlimb tumors grown in $\mathrm{C} 3 \mathrm{H}$ mice were injected with a single intravenous dose $(250 \mu \mathrm{g}$ TNF- $\alpha / \mathrm{kg})$ of CYT-6091 4 hours prior to heating for $60 \mathrm{~min}$ at $42.5^{\circ} \mathrm{C}$ using a water bath. These preclinical studies in mice showed significant increases in heat-induced tumor growth delay with CYT-6091 pre-conditioning prior to hyperthermic treatment (Figure 3C) [40, 41]. Up to 80\% reduction in tumor blood flow, as assessed by uptake of the radioactive tracer rubidium, was also measured at 4 hours after CYT-6091 injection that is consistent with known localized mechanisms of TNF- $\alpha$ vascular effects and damage in tumors (Figure 3A-B). This accentuation of hyperthermic injury also shows clear dose dependency. Our group has also conducted preliminary translational studies using VX2 tumors grown in rabbit kidneys. Administering CYT-6091 prior to RFA yielded a significantly larger zone of central necrosis (i.e. $23 \%$ increase in ablation volume) than RFA treatment alone on histological evaluation 3 days after the procedure. Control tumors that were not treated with RFA also showed a significant reduction in tumor volume after CYT-6091 treatment alone although not as much as RFA plus CYT-6091 group [82, 83]. This reduction in tumor volume after CYT-6091 treatment alone within 3 days usually occurs after multiple injections over time and may be attributed to the unique nature of the VX2 tumor physiology (i.e. more susceptible) [43]. Typically, our in vivo studies in mice yield significantly less tumor growth delay when CYT-6091 is administered without thermal therapy [40, 41]. Clinically, a multiple dosing schedule was used in a Phase I trial in which CYT-6091 was administered as a standalone cancer therapeutic [42, 43].

\section{Nanoparticle Enhanced Cryosurgery}

We have also extensively investigated CYT-6091 particles for pre-conditioning tumors to enhance cryosurgical injury in preclinical models. Cryosurgery was conducted using a Joule-Thomson based argon cryoprobe with the tip temperature maintained at $-100^{\circ} \mathrm{C}$. Systemic injection of $200 \mu \mathrm{g}$ TNF- $\alpha / \mathrm{kg}$ of CYT-6091 4 hours prior to cryosurgery of human prostate cancer xenograft (LNCaP Pro 5) and uterine fibroid (ELT-3) tumors grown in hindlimb of nude mice resulted in significant tumor growth delay and in some cases 
complete remission compared to mice injected with an equivalent dose of native TNF- $\alpha$ or the control nanoparticle without TNF- $\alpha$ (Figure 3C, 5) [84, 85]. Furthermore, mice administered with CYT-6091 displayed no overt toxicity whereas nearly $25 \%$ of mice injected with native TNF- $\alpha$ prior to cryosurgery died within several hours after the therapy. Since tumor kill by cryosurgery is highly dependent on the temperature and rate of temperature change experienced by the tumor, in subsequent studies we used the dorsal skin fold chamber (DSFC) tumor model coupled with real time infrared imaging and thermocouple measurements to obtain the spatial temperature profile of the tumor tissue during and immediately after cryosurgery. Similar to hyperthermic injury, we also discovered a dose-dependence of CYT-6091 for enhancement of cryosurgical injury [84, 85]. In a pilot translational study using VX2 tumors grown in rabbit kidneys, we also obtained a significant decrease in the rate of peritoneal carcinomatosis (metastases) in animals treated with cryosurgery and CYT-6091 compared to cryosurgery alone [82]. This was an unexpected finding and further investigations are underway in preclinical tumor models to interpret whether this was a direct effect on mechanisms of tumor spread or a stimulation of antitumor immunity.

\section{Potential for Enhanced Imaging by Nanoparticle Pre-Conditioning}

While we have shown that nanoparticle pre-conditioning is capable of enhancing both hyperthermic and cryosurgical injury in solid tumors, another important potential of this concept lies in its ability to enhance the clinical imaging techniques associated with thermal therapies. For instance, pre-conditioning events can be imaged to provide longitudinal monitoring of the state of pre-conditioning to optimize the time of administration of the secondary treatment. We have already shown that the administration of CYT-6091 is accompanied by a significant $80 \%$ reduction in tumor perfusion [40, 41]. Hence, current imaging technologies such as computed tomography (CT), magnetic resonance imaging (MR) or even contrast enhanced ultrasound (CEUS) may prove useful in measuring perfusion drops associated with pre-conditioning that signal an optimal timing for thermal therapy [86, 87]. Similarly, the development of myeloperoxidase-specific imaging agents offers the unique opportunity of monitoring the tumor biology before and after therapy by imaging the recruitment of neutrophils into the tumor tissue [88, 89]. Recent data collected in our lab has shown, on histology, the presence of a neutrophil rich inflammatory infiltrate that peaks at day 3 after TNF- $\alpha$ enhanced cryosurgery (Figure 6A-B) [65]. In this work, $\mathrm{LNCaP}$ tumors were grown in DSFCs implanted on nude mice. Tumors were preconditioned using topical administration of 200 ng native TNF- $\alpha 4$ hours prior to cryosurgery. Intravital imaging, thermography, and post-sacrifice histology and immunohistochemistry were used to longitudinally assess iceball location and the ensuing biological effects (e.g. neutrophil infiltration) after cryosurgery with and without TNF- $\alpha$ pretreatment within the DSFC tumor tissue. In a separate experiment using TRAMP-C2 tumors grown subcutaneously in nude mice, we have also shown that this recruitment of neutrophils to the tumor site post cryosurgery can be non-invasively imaged using luminol bioluminescence imaging (Figure 6C, unpublished results). Based on these preliminary findings, we speculate that the enhancement of neutrophil recruitment by nanoparticle preconditioning can be imaged and quantified using myeloperoxidase-specific imaging agents. Additionally, since we have shown that these pre-conditioning events (perfusion drop and neutrophil recruitment) persist and are enhanced after thermal therapy, we hypothesize that they may be used to quantify treatment effects and serve as prognostic indicators of the outcome of thermal therapy. This hypothesis is the basis of ongoing work in our group.

Nanoparticle pre-conditioning can also be used to predict the lethality of the thermal therapy in the case of cryosurgery. Many clinical imaging technologies including ultrasound, CT and MR easily distinguish the edge of the cryosurgical iceball in vivo [90]. Unfortunately, the 
current guideline for cancer destruction by freezing requires temperatures below a critical $-40{ }^{\circ} \mathrm{C}$ isotherm $[91,92]$. This is achieved in less than $50 \%$ of the total 3D iceball volume, assuming the iceball to be roughly elliptical and the probe temperature to be roughly -160 ${ }^{\circ} \mathrm{C}$ [93]. It has understandably led to confusion about how much of the tissue and/or cancer to freeze during cryosurgery. This confusion persists today and undoubtedly contributes to under and over freezing that yield local recurrence and complications respectively. With nanoparticle pre-conditioning, we have shown in the DSFC model that we can move the tissue-destruction isotherm to $-0.5^{\circ} \mathrm{C}$, suggesting that cryosurgical destruction can be effectively doubled and intra-operative imaging of the iceball correlates to destruction, since in such conditions, "what you see (iceball) is what you get (destruction)" [84, 94]. This finding also translated to the hindlimb model in which cryosurgery was performed until the edge of the iceball overlapped with the visible edge of the tumor yielding apparent remission in a significant percent of animals (Figure 5) [84]. These data suggest the clinical use of a nanoparticle system, such as CYT-6091, could enable the surgeon for the first time to visualize the zone of tumor destruction by simply imaging the ice formation during cryosurgery.

\section{Conclusions}

The concept of pre-conditioning the tumor microenvironment using nanoparticles is relatively new and many avenues of basic and clinical research particularly for use in the field of thermal therapy enhancement remain largely open. Our group has demonstrated the use of a gold nanoparticle system (CYT-6091), which has recently completed a Phase I clinical trial and moved into Phase II as a standalone cancer therapeutic, to pre-condition a variety of preclinical tumor models prior to thermal therapies (using both heat and cold) (Table 4). Pharmacokinetic and biodistribution studies of CYT-6091 have shown tumorspecific drug and nanoparticle localization and we have demonstrated that a single systemic injection of the nanoparticle at a critical time period (4 hours) prior to thermal therapy suffices to pre-condition the tumor with no overt toxicity. Further, vascular (perfusion defect) and immunological (leukocyte recruitment) mechanisms responsible for preconditioning using CYT-6091 have been demonstrated by various techniques and suggest imaging as a possible clinical tool for assessment of the optimal time for subsequent thermal therapy intervention. Thermal therapy outcomes after appropriate pre-conditioning with CYT-6091 have been able to induce tumor regression without toxicity (Table 4, Figures 3, 5), establishing the validity of this clinically realistic approach.

\section{Future Perspective}

The constantly evolving and heterogeneous nature of cancer has resulted in a shift from single agent therapy to multi-drug regimens and combinatorial therapies for improved local and metastatic control. This is particularly true for thermal therapy in cancer which is currently dominated by regional hyperthermia combined with standard-of-care chemotherapy and/or radiotherapy for a wide variety of tumors. More recently, focused minimally invasive thermal therapy approaches such as cryosurgery, microwave, and radiofrequency ablation (Table 2) are also finding favor with clinicians and several clinical trials are in progress to test the efficacy of combinatorial therapy using these techniques with chemotherapeutics. A small subset of these trials involves thermal therapies with commercially manufactured nanoparticles (Table 1 ). This subset of clinical trials represents the successful realization of preclinical research efforts over the past decade in nanomedicine and heralds a new future in cancer therapy. Some of the key challenges going forward are: (1) selection of the appropriate nanoparticle, pre-conditioning agent and thermal therapy for the specific tumor type; (2) demonstration of selective nanoparticle delivery, safety and efficacy and expanded understanding of nanomedicine toxicological 
considerations; (3) timing and guidance of thermal therapy perhaps by imaging preconditioning after nanoparticle administration; and (4) controlling the extent of thermal intervention necessary to kill the tumor. As we await future nanoparticle development and optimization, even today there may be few barriers to the use of existing manufactured nanoparticles (i.e. CYT-6091) to pre-condition and treat solid cancers with thermal therapies in Phase I/II clinical trials.

\section{Acknowledgments}

This work was supported by funds from the National Institutes of Health (project\#: R01CA075284 and R01CA44114) and Institute for Engineering in Medicine (University of Minnesota). The authors thank Raghav Goel and Rachana Visaria for valuable discussions and preliminary work on the pre-conditioning concept. CYT-6091 nanoparticles were a kind gift from CytImmune Sciences, Inc (Rockville, Maryland, USA). Special thanks to Warren Chan and Mehmet Toner for useful discussions about this work.

\section{References}

- of interest

$\bullet$ of considerable interest

1. Ferrari M. Cancer nanotechnology: opportunities and challenges. Nat Rev Cancer. 2005; 5(3):161171. [PubMed: 15738981]

2. Nie S, Xing Y, Kim GJ, Simons JW. Nanotechnology applications in cancer. Annu Rev Biomed Eng. 2007; 9:257-288. [PubMed: 17439359]

3. Xie J, Lee S, Chen X. Nanoparticle-based theranostic agents. Adv Drug Deliv Rev. 2010

4. Juzenas P, Chen W, Sun YP, et al. Quantum dots and nanoparticles for photodynamic and radiation therapies of cancer. Adv Drug Deliv Rev. 2008; 60(15):1600-1614. [PubMed: 18840487]

5. Cancer Facts \& Figures 2009. Atlanta: American Cancer Society; 2009.

6. VanSonnenberg, E.; McMullen, W.; Solbiati, L., editors. Tumor Ablation: Principles and Practice. New York: Springer; 2005.

7. Mulier S, Ni Y, Jamart J, Ruers T, Marchal G, Michel L. Local recurrence after hepatic radiofrequency coagulation: multivariate meta-analysis and review of contributing factors. Ann Surg. 2005; 242(2):158-171. [PubMed: 16041205]

8. Jones JS, Rewcastle JC, Donnelly BJ, Lugnani FM, Pisters LL, Katz AE. Whole gland primary prostate cryoablation: initial results from the cryo on-line data registry. J Urol. 2008; 180(2):554558. [PubMed: 18550117]

9. Dewey WC. Arrhenius relationships from the molecule and cell to the clinic. Int J Hyperthermia. 1994; 10(4):457-483. [PubMed: 7963805]

10. Gage AA, Baust JG. Cryosurgery for tumors. J Am Coll Surg. 2007; 205(2):342-356. [PubMed: 17660083]

11. Day ES, Morton JG, West JL. Nanoparticles for thermal cancer therapy. J Biomech Eng. 2009; 131(7) 074001.

12. Gilchrist RK, Medal R, Shorey WD, Hanselman RC, Parrott JC, Taylor CB. Selective inductive heating of lymph nodes. Ann Surg. 1957; 146(4):596-606. [PubMed: 13470751]

13. Maier-Hauff K, Rothe R, Scholz R, et al. Intracranial thermotherapy using magnetic nanoparticles combined with external beam radiotherapy: results of a feasibility study on patients with glioblastoma multiforme. J Neurooncol. 2007; 81(1):53-60. [PubMed: 16773216]

14. Johannsen M, Gneveckow U, Taymoorian K, et al. Morbidity and quality of life during thermotherapy using magnetic nanoparticles in locally recurrent prostate cancer: results of a prospective phase I trial. Int J Hyperthermia. 2007; 23(3):315-323. [PubMed: 17523023]

15. Zharov VP, Galitovskaya EN, Johnson C, Kelly T. Synergistic enhancement of selective nanophotothermolysis with gold nanoclusters: potential for cancer therapy. Lasers Surg Med. 2005; 37(3):219-226. [PubMed: 16175635] 
16. Skrabalak SE, Chen J, Au L, Lu X, Li X, Xia Y. Gold Nanocages for Biomedical Applications. Adv Mater Deerfield. 2007; 19(20):3177-3184.

17. Huang X, El-Sayed IH, Qian W, El-Sayed MA. Cancer cell imaging and photothermal therapy in the near-infrared region by using gold nanorods. J Am Chem Soc. 2006; 128(6):2115-2120. [PubMed: 16464114]

18. Huang N, Wang H, Zhao J, Lui H, Korbelik M, Zeng H. Single-wall carbon nanotubes assisted photothermal cancer therapy: Animal study with a murine model of squamous cell carcinoma. Lasers Surg Med. 2010; 42(9):638-648. [PubMed: 20949599]

19. von Maltzahn G, Park JH, Agrawal A, et al. Computationally guided photothermal tumor therapy using long-circulating gold nanorod antennas. Cancer Res. 2009; 69(9):3892-3900. [PubMed: 19366797]

20. Zhou M, Zhang R, Huang M, et al. A Chelator-Free Multifunctional [(64)Cu]CuS Nanoparticle Platform for Simultaneous Micro-PET/CT Imaging and Photothermal Ablation Therapy. J Am Chem Soc. 2010; 132(43):15351-15358. [PubMed: 20942456]

21. Hirsch LR, Stafford RJ, Bankson JA, et al. Nanoshell-mediated near-infrared thermal therapy of tumors under magnetic resonance guidance. Proc Natl Acad Sci U S A. 2003; 100(23):13549_ 13554. [PubMed: 14597719]

22. Curley SA, Cherukuri P, Briggs K, et al. Noninvasive radiofrequency field-induced hyperthermic cytotoxicity in human cancer cells using cetuximab-targeted gold nanoparticles. J Exp Ther Oncol. 2008; 7(4):313-326. [PubMed: 19227011]

23. Byrne JD, Betancourt T, Brannon-Peppas L. Active targeting schemes for nanoparticle systems in cancer therapeutics. Adv Drug Deliv Rev. 2008; 60(15):1615-1626. [PubMed: 18840489]

24. Issels RD. Hyperthermia adds to chemotherapy. Eur J Cancer. 2008; 44(17):2546-2554. [PubMed: 18789678]

25. Griffin RJ, Ogawa A, Williams BW, Song CW. Hyperthermic enhancement of tumor radiosensitization strategies. Immunological investigations. 2005; 34(3):343-359. [PubMed: 16136785]

26. Dudar TE, Jain RK. Differential response of normal and tumor microcirculation to hyperthermia. Cancer Res. 1984; 44(2):605-612. [PubMed: 6692365]

27. Koning G, Eggermont A, Lindner L, ten Hagen T. Hyperthermia and Thermosensitive Liposomes for Improved Delivery of Chemotherapeutic Drugs to Solid Tumors. Pharmaceutical Research. 2010; 27(8):1750-1754. [PubMed: 20424894] . Review paper discussing the progress made in combinatorial therapy using hyperthermia and nanoparticle delivered chemotherapeutic.

28. Lin JC, Yuan PMK, Jung DT. Enhancement of anticancer drug delivery to the brain by microwave induced hyperthermia. Bioelectrochemistry and Bioenergetics. 1998; 47(2):259-264.

29. Franckena M, De Wit R, Ansink AC, et al. Weekly systemic cisplatin plus locoregional hyperthermia: an effective treatment for patients with recurrent cervical carcinoma in a previously irradiated area. Int J Hyperthermia. 2007; 23(5):443-450. [PubMed: 17701535]

30. Sneed PK, Stauffer PR, McDermott MW, et al. Survival benefit of hyperthermia in a prospective randomized trial of brachytherapy boost $+/-$ hyperthermia for glioblastoma multiforme. Int $\mathbf{J}$ Radiat Oncol Biol Phys. 1998; 40(2):287-295. [PubMed: 9457811]

31. van der Zee J, Gonzalez GD, van Rhoon GC, van Dijk JD, van Putten WL, Hert AA. Comparison of radiotherapy alone with radiotherapy plus hyeprthermia in locally advanced pelvic tumors: a prospective, randomized, multicentre trial. Dutch Deep Hyperthemic Group. Lancet. 2000; 355(9210):1119-1125. [PubMed: 10791373]

32. Colombo R, Da Pozzo LF, Salonia A, et al. Multicentric study comparing intravesical chemotherapy alone and with local microwave hyperthermia for prophylaxis of recurrence of superficial transitional cell carcinoma. J Clin Oncol. 2003; 21(23):4270-4276. [PubMed: 14581436]

33. Ponce AM, Vujaskovic Z, Yuan F, Needham D, Dewhirst MW. Hyperthermia mediated liposomal drug delivery. Int J Hyperthermia. 2006; 22(3):205-213. [PubMed: 16754340]

34. Goldberg SN, Kamel IR, Kruskal JB, et al. Radiofrequency ablation of hepatic tumors: increased tumor destruction with adjuvant liposomal doxorubicin therapy. AJR Am J Roentgenol. 2002; 179(1):93-101. [PubMed: 12076912] 
35. Ahmed M, Lukyanov AN, Torchilin V, Tournier H, Schneider AN, Goldberg SN. Combined radiofrequency ablation and adjuvant liposomal chemotherapy: effect of chemotherapeutic agent, nanoparticle size, and circulation time. J Vasc Interv Radiol. 2005; 16(10):1365-1371. [PubMed: 16221908]

36. Schwerdt A, Zintchenko A, Concia M, et al. Hyperthermia-induced targeting of thermosensitive gene carriers to tumors. Hum Gene Ther. 2008; 19(11):1283-1292. [PubMed: 19866491]

37. Zhang W, Rong J, Wang Q, He X. The encapsulation and intracellular delivery of trehalose using a thermally responsive nanocapsule. Nanotechnology. 2009; (27):275101. [PubMed: 19528681]

38. Hanna E, Quick J, Libutti SK. The tumour microenvironment: a novel target for cancer therapy. Oral Dis. 2009; 15(1):8-17. [PubMed: 18992016]

39. Jiang J, Goel R, Iftekhar MA, et al. Tumor necrosis factor-\{alpha\}-induced accentuation in cryoinjury: mechanisms in vitro and in vivo. Mol Cancer Ther. 2008; 7(8):2547-2555. [PubMed: 18723499]

40. Visaria R, Bischof JC, Loren M, et al. Nanotherapeutics for enhancing thermal therapy of cancer. Int J Hyperthermia. 2007; 23(6):501-511. [PubMed: 17952764]

41. Visaria RK, Griffin RJ, Williams BW, et al. Enhancement of tumor thermal therapy using gold nanoparticle-assisted tumor necrosis factor- $\{$ alpha $\}$ delivery. Mol Cancer Ther. 2006; 5(4):10141020. [PubMed: 16648573] . This paper reports (discussed in text) on the first use of CYT-6091 as a pre-conditioning agent for hyperthermia of solid tumors.

42. Libutti SK, Paciotti GF, Myer L, et al. Results of a completed phase I clinical trial of CYT-6091: A pegylated colloidal gold-TNF nanomedicine. J Clin Oncol (Meeting Abstracts). 2009; 27(15S): 3586.

43. Libutti SK, Paciotti GF, Byrnes AA, et al. Phase I and Pharmacokinetic Studies of CYT-6091, a Novel PEGylated Colloidal Gold-rhTNF Nanomedicine. Clin Cancer Res. 2010. Report on results of the first Phase I clinical trial using CYT-6091 as standalone therapy for cancer.

44. van Horssen R, Ten Hagen TL, Eggermont AM. TNF-alpha in cancer treatment: molecular insights, antitumor effects, and clinical utility. Oncologist. 2006; 11(4):397-408. [PubMed: 16614236]

45. Lin JC, Park HJ, Song CW. Combined treatment of IL-1 alpha and TNF-alpha potentiates the antitumour effect of hyperthermia. Int J Hyperthermia. 1996; 12(3):335-344. [PubMed: 9044903]

46. Sun Z, Yan J, Rao W, Liu J. Particularities of tissue types in treatment planning of nano cryosurgery. 2008 In.

47. Shalkevich N, Escher W, Bu rgi T, Michel B, Si-Ahmed L, Poulikakos D. On the Thermal Conductivity of Gold Nanoparticle Colloids. Langmuir. 2009; 26(2):663-670. [PubMed: 19681632]

48. Goel R, Shah N, Visaria R, Paciotti GF, Bischof JC. Biodistribution of TNF-alpha-coated gold nanoparticles in an in vivo model system. Nanomed. 2009; 4(4):401-410.

49. Perrault SD, Walkey C, Jennings T, Fischer HC, Chan WC. Mediating tumor targeting efficiency of nanoparticles through design. Nano Lett. 2009; 9(5):1909-1915. [PubMed: 19344179]

50. De Jong WH, Hagens WI, Krystek P, Burger MC, Sips AJ, Geertsma RE. Particle size-dependent organ distribution of gold nanoparticles after intravenous administration. Biomaterials. 2008; 29(12):1912-1919. [PubMed: 18242692]

51. James W, Hirsch L, West J, O’Neal P, Payne J. Application of INAA to the build-up and clearance of gold nanoshells in clinical studies in mice. Journal of Radioanalytical and Nuclear Chemistry. 2007; 271(2):455-459.

52. Petros RA, DeSimone JM. Strategies in the design of nanoparticles for therapeutic applications. Nat Rev Drug Discov. 2010; 9(8):615-627. [PubMed: 20616808]

53. Paciotti GF, Myer L, Weinreich D, et al. Colloidal gold: a novel nanoparticle vector for tumor directed drug delivery. Drug Deliv. 2004; 11(3):169-183. [PubMed: 15204636]

54. Shah NB, Dong J, Bischof JC. Cellular uptake and nanoscale localization of gold nanoparticles in cancer using label free Confocal Raman Microscopy. Mol Pharm. 2010

55. Pober JS, Sessa WC. Evolving functions of endothelial cells in inflammation. Nat Rev Immunol. 2007; 7(10):803-815. [PubMed: 17893694] 
56. ten Hagen TL, Seynhaeve AL, Eggermont AM. Tumor necrosis factor-mediated interactions between inflammatory response and tumor vascular bed. Immunol Rev. 2008; 222:299-315. [PubMed: 18364010]

57. Farma JM, Puhlmann M, Soriano PA, et al. Direct evidence for rapid and selective induction of tumor neovascular permeability by tumor necrosis factor and a novel derivative, colloidal gold bound tumor necrosis factor. Int J Cancer. 2007; 120(11):2474-2480. [PubMed: 17330231]

58. Griffin RJ, Lee SH, Rood KL, et al. Use of arsenic trioxide as an antivascular and thermosensitizing agent in solid tumors. Neoplasia. 2000; 2(6):555-560. [PubMed: 11228548]

59. Griffin RJ, Monzen H, Williams BW, Park H, Lee SH, Song CW. Arsenic trioxide induces selective tumour vascular damage via oxidative stress and increases thermosensitivity of tumours. Int J Hyperthermia. 2003; 19(6):575-589. [PubMed: 14756449]

60. Griffin RJ, Williams BW, Bischof JC, Olin M, Johnson GL, Lee BW. Use of a fluorescently labeled poly-caspase inhibitor for in vivo detection of apoptosis related to vascular-targeting agent arsenic trioxide for cancer therapy. Technol Cancer Res Treat. 2007; 6(6):651-654. [PubMed: 17994796]

61. Hines-Peralta A, Sukhatme V, Regan M, Signoretti S, Liu ZJ, Goldberg SN. Improved tumor destruction with arsenic trioxide and radiofrequency ablation in three animal models. Radiology. 2006; 240(1):82-89. [PubMed: 16720872]

62. Hinnen P, Eskens FA. Vascular disrupting agents in clinical development. Br J Cancer. 2007; 96(8):1159-1165. [PubMed: 17375046]

63. Siemann DW. The unique characteristics of tumor vasculature and preclinical evidence for its selective disruption by Tumor-Vascular Disrupting Agents. Cancer Treatment Reviews. 2010 In Press, Corrected Proof. . Review of the preclinical evidence for the use of potential preconditioning agents, i.e. vascular destructive agents, for solid tumor therapy.

64. Shalaby MR, Palladino MA Jr, Hirabayashi SE, et al. Receptor binding and activation of polymorphonuclear neutrophils by tumor necrosis factor-alpha. J Leukoc Biol. 1987; 41(3):196204. [PubMed: 3031189]

65. Jiang J, Goel R, Schmechel S, Vercellotti G, Forster C, Bischof J. Pre-Conditioning Cryosurgery: Cellular and Molecular Mechanisms and Dynamics of TNF-alpha Enhanced Cryotherapy in an in vivo Prostate Cancer Model System. Cryobiology. 2010

66. Di Carlo E, Forni G, Lollini P, Colombo MP, Modesti A, Musiani P. The intriguing role of polymorphonuclear neutrophils in antitumor reactions. Blood. 2001; 97(2):339-345. [PubMed: 11154206]

67. Allavena P, Sica A, Garlanda C, Mantovani A. The Yin-Yang of tumor-associated macrophages in neoplastic progression and immune surveillance. Immunol Rev. 2008; 222:155-161. [PubMed: 18364000]

68. Boon T, Coulie PG, Van den Eynde BJ, van der Bruggen P. Human T cell responses against melanoma. Annu Rev Immunol. 2006; 24:175-208. [PubMed: 16551247]

69. Balza E, Mortara L, Sassi F, et al. Targeted delivery of tumor necrosis factor-alpha to tumor vessels induces a therapeutic T cell-mediated immune response that protects the host against syngeneic tumors of different histologic origin. Clin Cancer Res. 2006; 12(8):2575-2582. [PubMed: 16638868]

70. Yang JC, Hughes M, Kammula U, et al. Ipilimumab (anti-CTLA4 antibody) causes regression of metastatic renal cell cancer associated with enteritis and hypophysitis. J Immunother. 2007; 30(8): 825-830. [PubMed: 18049334]

71. Lei C, Liu P, Chen B, et al. Local release of highly loaded antibodies from functionalized nanoporous support for cancer immunotherapy. J Am Chem Soc. 2010; 132(20):6906-6907. [PubMed: 20433206]

72. Hoffmann NE, Bischof JC. The cryobiology of cryosurgical injury. Urology. 2002; 60(2 Suppl 1): 40-49. [PubMed: 12206847]

73. Nikfarjam M, Muralidharan V, Christophi C. Mechanisms of focal heat destruction of liver tumors. Journal of Surgical Research. 2005; 127(2):208-223. [PubMed: 16083756]

74. Gage AA, Baust JM, Baust JG. Experimental cryosurgery investigations in vivo. Cryobiology. 2009; 59(3):229-243. [PubMed: 19833119] 
75. Lepock J. Cellular effects of hyperthermia: relevance to the minimum dose for thermal damage. International Journal of Hyperthermia. 2003; 19(3):252-266. [PubMed: 12745971]

76. Coad JE, Kosari K, Humar A, Sielaff TD. Radiofrequency ablation causes 'thermal fixation' of hepatocellular carcinoma: a post-liver transplant histopathologic study. Clinical Transplantation. 2003; 17(4):377-384. [PubMed: 12868996]

77. Gazzaniga S, Bravo A, Goldszmid S, et al. Inflammatory changes after cryosurgery-induced necrosis in human melanoma xenografted in nude mice. Journal of Investigative Dermatology. 2001; 116(5):664-671. [PubMed: 11348453]

78. Esmon C. The interactions between inflammation and coagulation. British journal of haematology. 2005; 131(4):417-430. [PubMed: 16281932]

79. Sabel MS. Cryo-immunology: a review of the literature and proposed mechanisms for stimulatory versus suppressive immune responses. Cryobiology. 2009; 58(1):1-11. [PubMed: 19007768]

80. Skitzki JJ, Repasky EA, Evans SS. Hyperthermia as an immunotherapy strategy for cancer. Curr Opin Investig Drugs. 2009; 10(6):550-558.

81. Gallucci S, Lolkema M, Matzinger P. Natural adjuvants: endogenous activators of dendritic cells. Nat Med. 1999; 5(11):1249-1255. [PubMed: 10545990]

82. Shenoi MM, Anderson JK, Bischof JC. Nanoparticle enhanced thermal therapies. Engineering in Medicine and Biology Society, 2009. EMBC 2009. Annual International Conference of the IEEE. 2009 Sept 3-6.

83. Pedro RN, Thekke-Adiyat T, Goel R, et al. Use of Tumor Necrosis Factor-alpha-coated Gold Nanoparticles to Enhance Radiofrequency Ablation in a Translational Model of Renal Tumors. Urology. 76(2):494-498. [PubMed: 20451965]

84. Goel R, Swanlund D, Coad J, Paciotti GF, Bischof JC. TNF-\{alpha $\}$-based accentuation in cryoinjury--dose, delivery, and response. Mol Cancer Ther. 2007; 6(7):2039-2047. [PubMed: 17620433] . This paper reports (discussed in text) on the first use of CYT-6091 as a preconditioning agent for cryosurgery of solid tumors.

85. Jiang J, Bischof J. Effect of timing, dose and interstitial versus nanoparticle delivery of tumor necrosis factor alpha in combinatorial adjuvant cryosurgery treatment of ELT-3 uterine fibroid tumor. Cryo Letters. 2010; 31(1):50-62. [PubMed: 20309509]

86. Seshadri M, Toth K. Acute vascular disruption by 5,6-dimethylxanthenone-4-acetic Acid in an orthotopic model of human head and neck cancer. Transl Oncol. 2009; 2(3):121-127. [PubMed: 19701496]

87. Salmon BA, Salmon HW, Siemann DW. Monitoring the treatment efficacy of the vascular disrupting agent CA4P. Eur J Cancer. 2007; 43(10):1622-1629. [PubMed: 17451938]

88. Gross S, Gammon ST, Moss BL, et al. Bioluminescence imaging of myeloperoxidase activity in vivo. Nat Med. 2009; 15(4):455-461. [PubMed: 19305414]

89. Rodriguez E, Nilges M, Weissleder R, Chen JW. Activatable magnetic resonance imaging agents for myeloperoxidase sensing: mechanism of activation, stability, and toxicity. J Am Chem Soc. 132(1):168-177. [PubMed: 19968300]

90. Rubinsky B. Cryosurgery. Annu Rev Biomed Eng. 2000; 2:157-187. [PubMed: 11701510]

91. Gage AA, Baust J. Mechanisms of tissue injury in cryosurgery. Cryobiology. 1998; 37(3):171186. [PubMed: 9787063]

92. Baust JG, Gage AA, Klossner D, et al. Issues critical to the successful application of cryosurgical ablation of the prostate. Technol Cancer Res Treat. 2007; 6(2):97-109. [PubMed: 17375972]

93. Rewcastle JC, Sandison GA, Hahn LJ, Saliken JC, McKinnon JG, Donnelly BJ. A model for the time-dependent thermal distribution within an iceball surrounding a cryoprobe. Phys Med Biol. 1998; 43(12):3519-3534. [PubMed: 9869029]

94. Chao BH, He X, Bischof JC. Pre-treatment inflammation induced by TNF-alpha augments cryosurgical injury on human prostate cancer. Cryobiology. 2004; 49(1):10-27. [PubMed: 15265713]

95. Powell AC, Paciotti GF, Libutti SK. Colloidal gold: a novel nanoparticle for targeted cancer therapeutics. Methods Mol Biol. 2010; 624:375-384. [PubMed: 20217609] 
96. Thamm DH, Kurzman ID, Clark MA, et al. Preclinical investigation of PEGylated tumor necrosis factor alpha in dogs with spontaneous tumors: phase I evaluation. Clin Cancer Res. 2010; 16(5): 1498-1508. [PubMed: 20160058]

97. Siemann DW, Chaplin DJ, Horsman MR. Vascular-targeting therapies for treatment of malignant disease. Cancer. 2004; 100(12):2491-2499. [PubMed: 15197790]

98. Horsman MR, Murata R. Combination of vascular targeting agents with thermal or radiation therapy. Int J Radiat Oncol Biol Phys. 2002; 54(5):1518-1523. [PubMed: 12459380]

99. Murata R, Overgaard J, Horsman MR. Potentiation of the anti-tumour effect of hyperthermia by combining with the vascular targeting agent 5,6-dimethylxanthenone-4-acetic acid. Int $\mathrm{J}$ Hyperthermia. 2001; 17(6):508-519. [PubMed: 11719967]

100. Kumar, V.; Fausto, N.; Abbas, A. Robbins \& Cotran Pathologic Basis of Disease. Seventh Edition. (7). Saunders; 2004.

101. Adams R, Schachtrup C, Davalos D, Tsigelny I, Akassoglou K. Fibrinogen signal transduction as a mediator and therapeutic target in inflammation: lessons from multiple sclerosis. Current Medicinal Chemistry. 2007; 14(27):2925-2936. [PubMed: 18045138]

102. Pallavicini MG, Hill RP. Effect of tumor blood flow manipulations on radiation response. Int $\mathbf{J}$ Radiat Oncol Biol Phys. 1983; 9(9):1321-1325. [PubMed: 6411662]

103. Kano MR, Bae Y, Iwata C, et al. Improvement of cancer-targeting therapy, using nanocarriers for intractable solid tumors by inhibition of TGF-beta signaling. Proc Natl Acad Sci U S A. 2007; 104(9):3460-3465. [PubMed: 17307870]

104. Garay RP, Viens P, Bauer J, et al. Cancer relapse under chemotherapy: why TLR2/4 receptor agonists can help. Eur J Pharmacol. 2007; 563(1-3):1-17. [PubMed: 17383632]

105. Moschella F, Proietti E, Capone I, Belardelli F. Combination strategies for enhancing the efficacy of immunotherapy in cancer patients. Ann N Y Acad Sci. 2010; 1194:169-178. [PubMed: 20536466]

106. Bouwhuis MG, Suciu S, Testori A, et al. Phase III trial comparing adjuvant treatment with pegylated interferon Alfa-2b versus observation: prognostic significance of autoantibodies-EORTC 18991. J Clin Oncol. 28(14):2460-2466. [PubMed: 20385998]

107. Agarwala SS, Glaspy J, O'Day SJ, et al. Results from a randomized phase III study comparing combined treatment with histamine dihydrochloride plus interleukin-2 versus interleukin-2 alone in patients with metastatic melanoma. J Clin Oncol. 2002; 20(1):125-133. [PubMed: 11773161]

108. Yang JC, Topalian SL, Schwartzentruber DJ, et al. The use of polyethylene glycol-modified interleukin-2 (PEG-IL-2) in the treatment of patients with metastatic renal cell carcinoma and melanoma. A phase I study and a randomized prospective study comparing IL-2 alone versus IL-2 combined with PEG-IL-2. Cancer. 1995; 76(4):687-694. [PubMed: 8625167]

109. Cocco C, Pistoia V, Airoldi I. New perspectives for melanoma immunotherapy: role of IL-12. Curr Mol Med. 2009; 9(4):459-469. [PubMed: 19519403]

110. Flavell RA, Sanjabi S, Wrzesinski SH, Licona-Limon P. The polarization of immune cells in the tumour environment by TGFbeta. Nat Rev Immunol. 2010; 10(8):554-567. [PubMed: 20616810]

111. Hennessy EJ, Parker AE, O'Neill LA. Targeting Toll-like receptors: emerging therapeutics? Nat Rev Drug Discov. 2010; 9(4):293-307. [PubMed: 20380038]

112. Redondo P, del Olmo J, Lopez-Diaz de Cerio A, et al. Imiquimod enhances the systemic immunity attained by local cryosurgery destruction of melanoma lesions. J Invest Dermatol. 2007; 127(7):1673-1680. [PubMed: 17380112]

113. den Brok MH, Sutmuller RP, Nierkens S, et al. Synergy between in situ cryoablation and TLR9 stimulation results in a highly effective in vivo dendritic cell vaccine. Cancer Res. 2006; 66(14): 7285-7292. [PubMed: 16849578]

114. Udagawa M, Kudo-Saito C, Hasegawa G, et al. Enhancement of immunologic tumor regression by intratumoral administration of dendritic cells in combination with cryoablative tumor pretreatment and Bacillus Calmette-Guerin cell wall skeleton stimulation. Clin Cancer Res. 2006; 12(24):7465-7475. [PubMed: 17189420]

115. Yamanaka R, Homma J, Yajima N, et al. Clinical evaluation of dendritic cell vaccination for patients with recurrent glioma: results of a clinical phase I/II trial. Clin Cancer Res. 2005; 11(11): 4160-4167. [PubMed: 15930352] 
116. Cubillos-Ruiz JR, Engle X, Scarlett UK, et al. Polyethylenimine-based siRNA nanocomplexes reprogram tumor-associated dendritic cells via TLR5 to elicit therapeutic antitumor immunity. $\mathrm{J}$ Clin Invest. 2009; 119(8):2231-2244. [PubMed: 19620771]

117. Dominguez AL, Lustgarten J. Targeting the tumor microenvironment with anti-neu/anti-CD40 conjugated nanoparticles for the induction of antitumor immune responses. Vaccine. 2010; 28(5): 1383-1390. [PubMed: 19931385]

118. Goel R, Paciotti GF, Bischof JC. Tumor necrosis factor-alpha induced enhancement of cryosurgery. Proceedings of SPIE. 2008; Vol 6842:68420R. 6842.

201. Celsion Corporation. http://www.celsion.com 


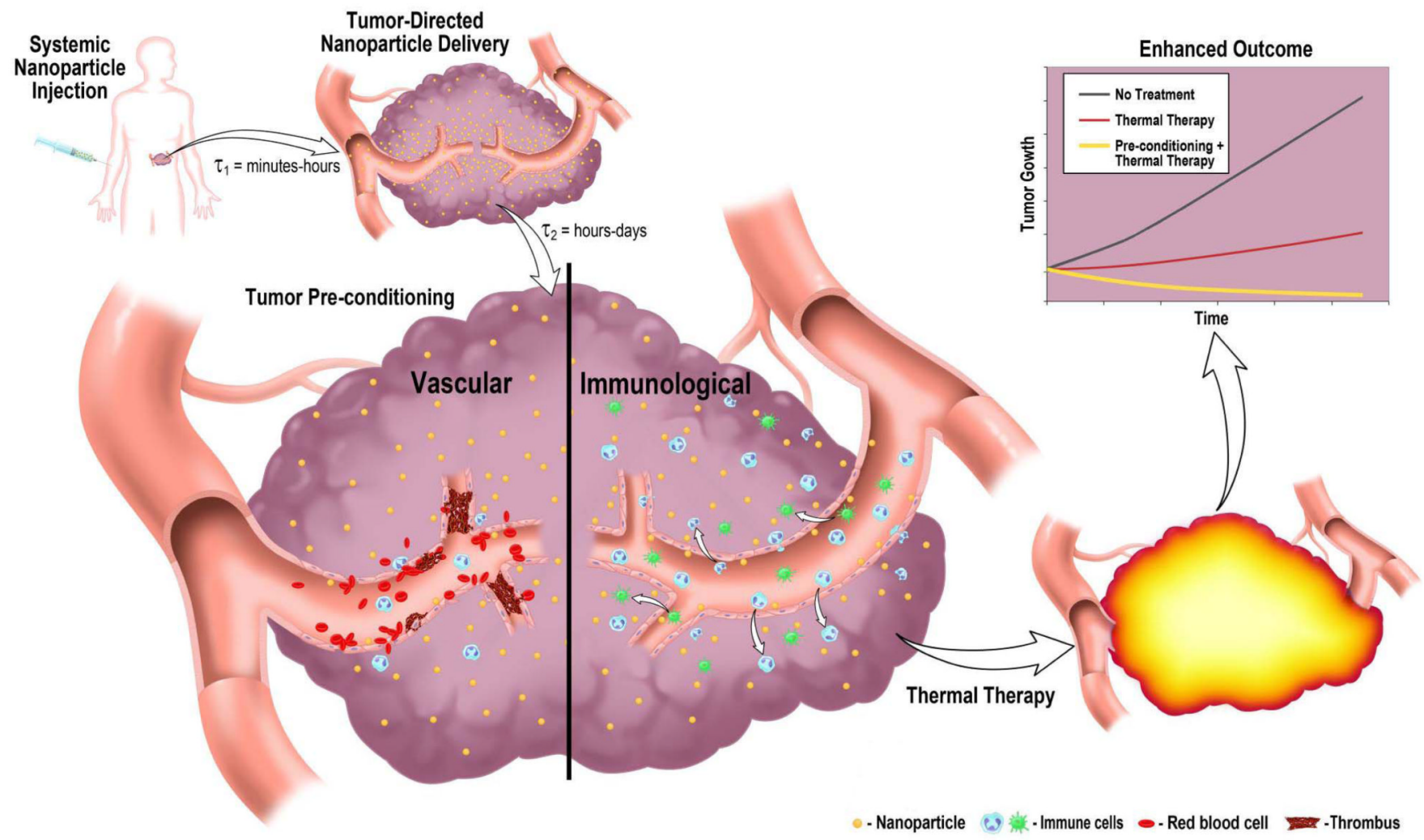

Figure 1. Nanoparticle Pre-conditioning of Tumor

Illustration of the concept of pre-conditioning the tumor using a bio-conjugated nanoparticle prior to thermal therapy for achieving enhanced tumor destruction. Systemic injection of the nanoparticle leads to its accumulation in the tumor within a short timeframe (minuteshours). Localization of the nanoparticle within the tumor initiates vascular and immunological pre-conditioning events (detailed in text) that reach peak response in a longer timeframe (hours-days). Thermal therapy (heat or cold) is then administered at an optimal time based on nanoparticle pre-conditioning to achieve superior tumor destruction over thermal therapy alone. 


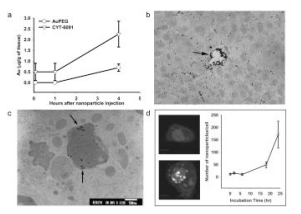

Figure 2. Nanoparticle Uptake in Cancer during Pre-conditioning

(a) Control NP and CYT-6091 accumulation in prostate tumors based on atomic emission spectroscopy (AES) measurements of gold. Presence of TNF- $\alpha$ on the nanoparticle increases its uptake in the tumor [48]. Results are expressed as mean \pm SD. (b) 8 hours post injection, $20 \mathrm{~nm}$ control nanoparticles migrate far into the interstitial space of the tumor from blood vessel (arrow) [49]. (c) Electron micrograph of prostate tumor 3 days post injection shows CYT-6091 NPs scattered around in tumor individually or in membrane bound organelles (arrows). (d) In vitro uptake analysis of LNCaP (prostate cancer) cells with confocal Raman microscopy shows no internalization of CYT-6091 at 2 hours (top) incubation whereas perinuclear localization (bottom, particles in green) after 24 hours of incubation. Quantitative analysis of cellular uptake via AES shows increasing cellular uptake over time (right). 
a
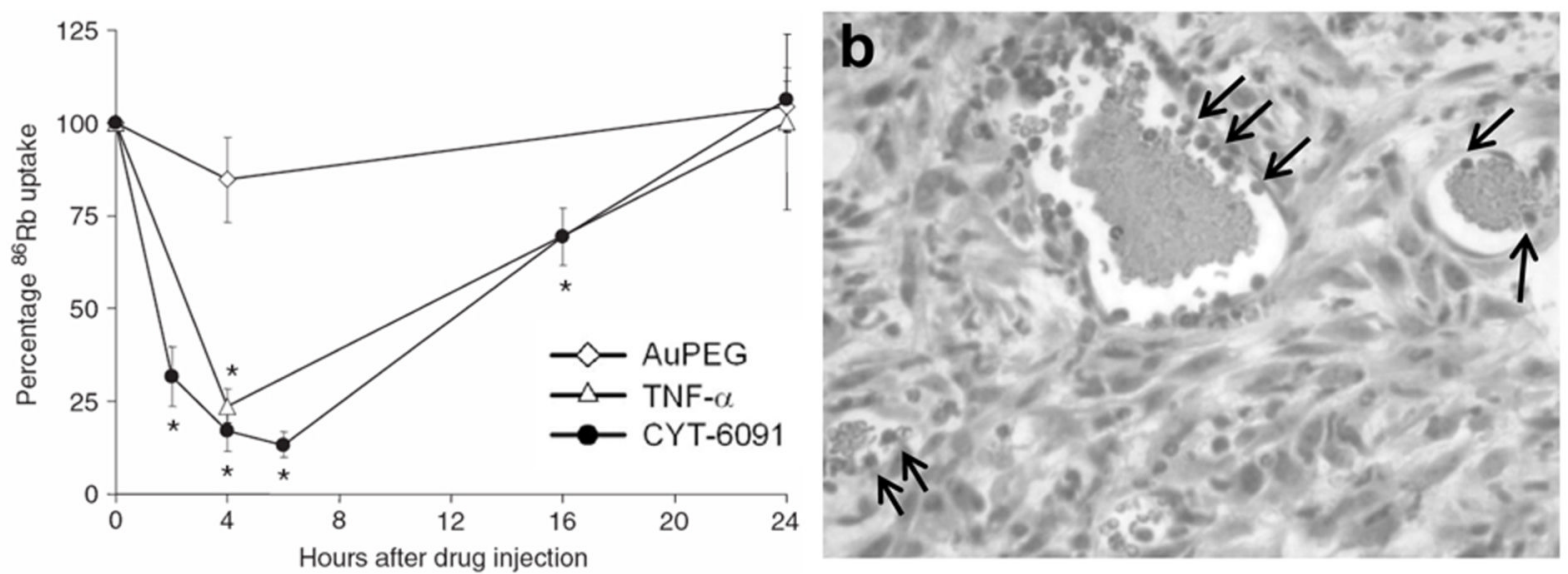

C

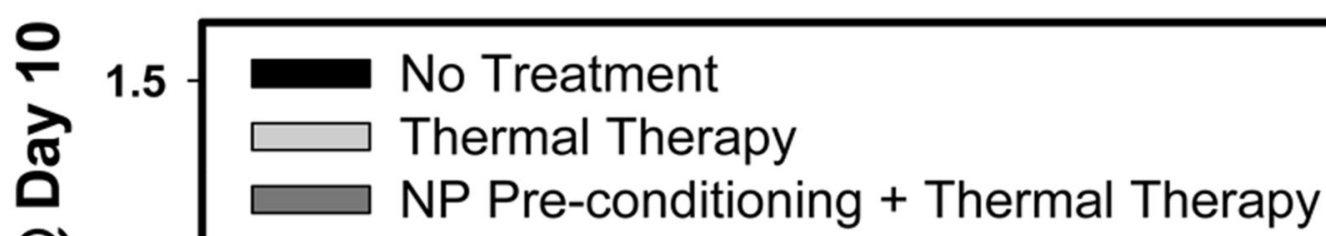

(C)

ํㅗㄹ

1.0

1.0
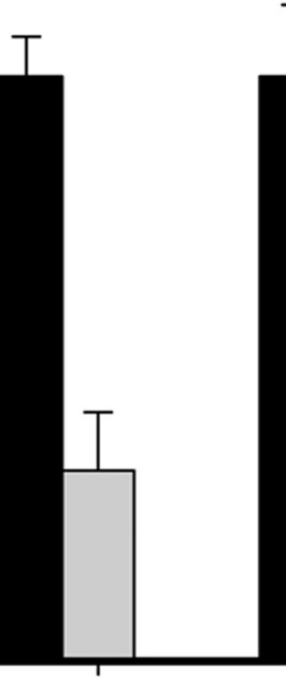

T

0.0

FSall

SCK

LNCaP

ELT-3

\section{Tumor Model}

Figure 3. Thermal Therapy Enhancement by Pre-conditioning with TNF- $\alpha$ Tagged Gold Nanoparticles

(a) Blood perfusion changes within SCK mammary carcinoma tumors assessed by uptake of radioactive rubidium in tumors after CYT-6091, TNF- $\alpha$ and Control NP systemic injection [40]. CYT-6091 produces the maximum decrease in tumor blood perfusion 4-6 hours after systemic injection. Results are expressed as mean \pm SEM and normalized to untreated controls. * Indicates statistically significant difference from untreated control. (b) H\&E stain of a TRAMP-C2 tumor grown in a dorsal skin fold chamber, 4 hours after topical administration of native TNF- $\alpha$, showing thrombus formation and neutrophil margination in blood vessels. (c) Tumor growth delay data with and without CYT-6091 pre-conditioning in 
pre-clinical tumor models: FSaII fibrosarcoma \& SCK mammary carcinoma with heat [40, 41] and LNCaP prostate carcinoma \& ELT-3 uterine leiomyoma with cryosurgery [84, 85]. Results are expressed as mean \pm SEM and normalized to control tumor volumes at Day 10 after therapy. In some cases, Day 10 volumes were linearly extrapolated from adjacent data points. * Indicates that Day 10 data is not available as tumors completely regressed by Day 4 [40]. 


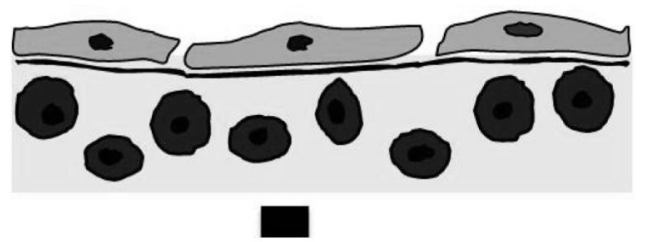

CYT-6091 nanoparticle administration
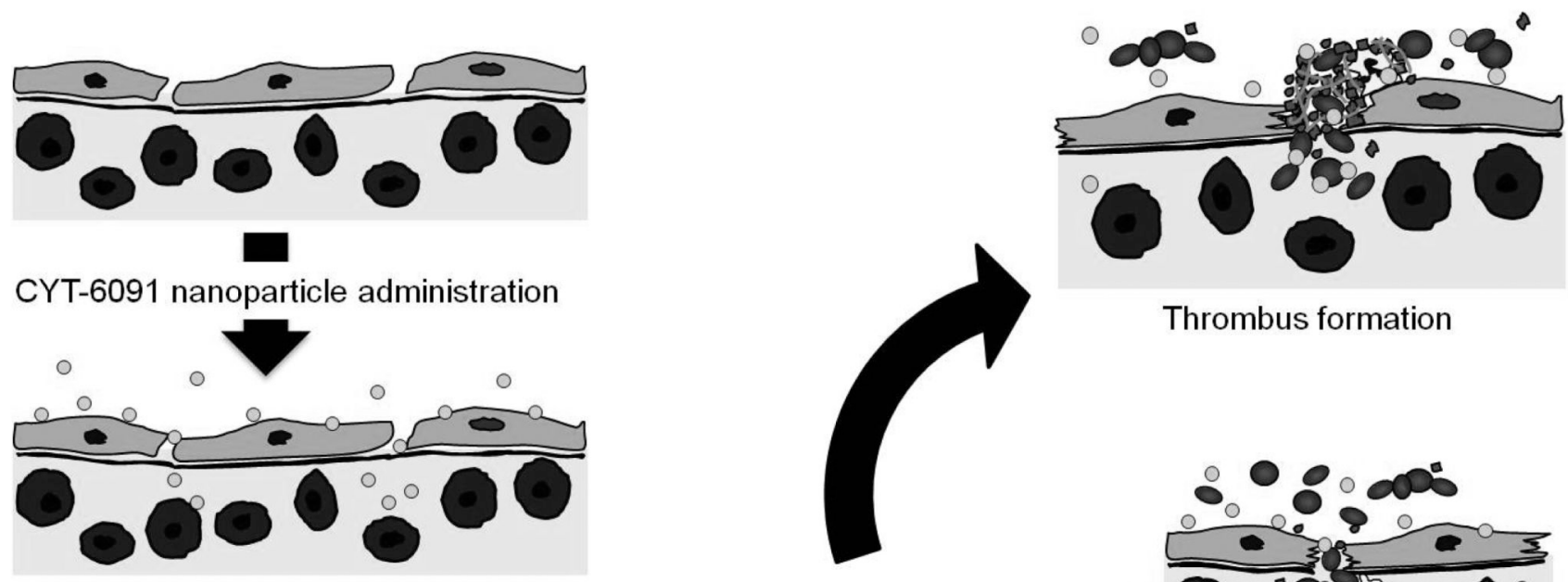

Thrombus formation
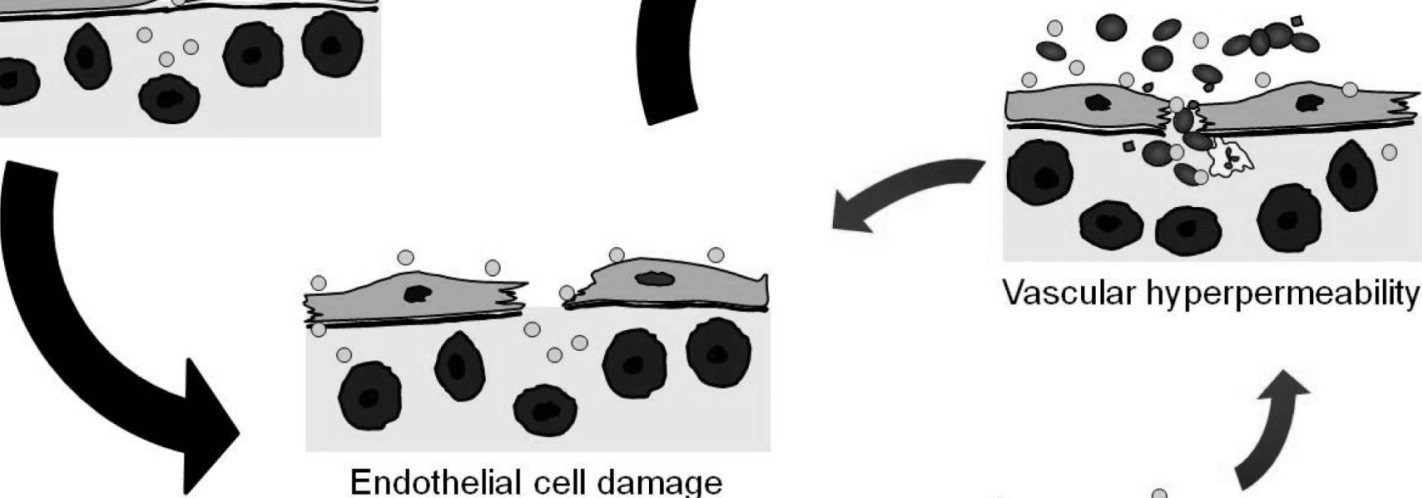

Vascular hyperpermeability

Endothelial cell damage
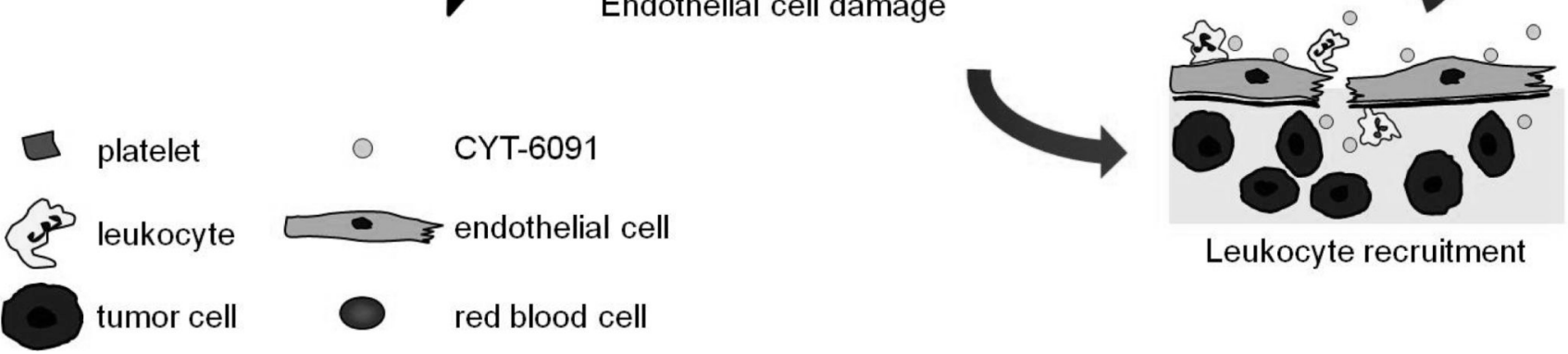

Leukocyte recruitment

Figure 4. Proposed Mechanism of Pre-conditioning with TNF- $\alpha$ Tagged Gold Nanoparticles Schematic showing interaction of CYT-6091 with tumor endothelium and cells leading to pro-inflammatory pre-conditioning events i.e. vascular hyperpermeability, recruitment of leukocytes (neutrophils, monocytes, lymphocytes), leukocyte-mediated endothelial cell injury, increased synthesis of tissue factor, increased procoagulant activity and decreased anticoagulant activity. 


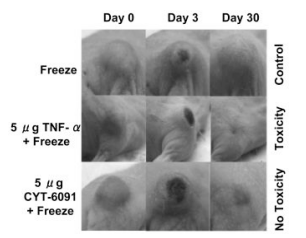

Figure 5. Cryosurgical Destruction of LNCaP Hindlimb Tumors

$200 \mu \mathrm{g}$ TNF- $\alpha / \mathrm{kg}$ of CYT-6091 was intravenously administered 4 hours prior to cryosurgery of LNCaP hindlimb tumors grown in nude mice. Cryosurgery was conducted using a JouleThomson based argon cryoprobe with the tip temperature maintained at $-100^{\circ} \mathrm{C}$.

Cryosurgery was conducted until the edge of the iceball overlapped the visual edge of the tumor. Toxicity (animal death) and tumor growth was monitored for a period of 30 days after treatment. The results show that CYT-6091 pre-conditioning followed by cryosurgery enables complete tumor regression without toxicity whereas significant toxicity is associated with native TNF- $\alpha$ pre-conditioning [84]. 
a
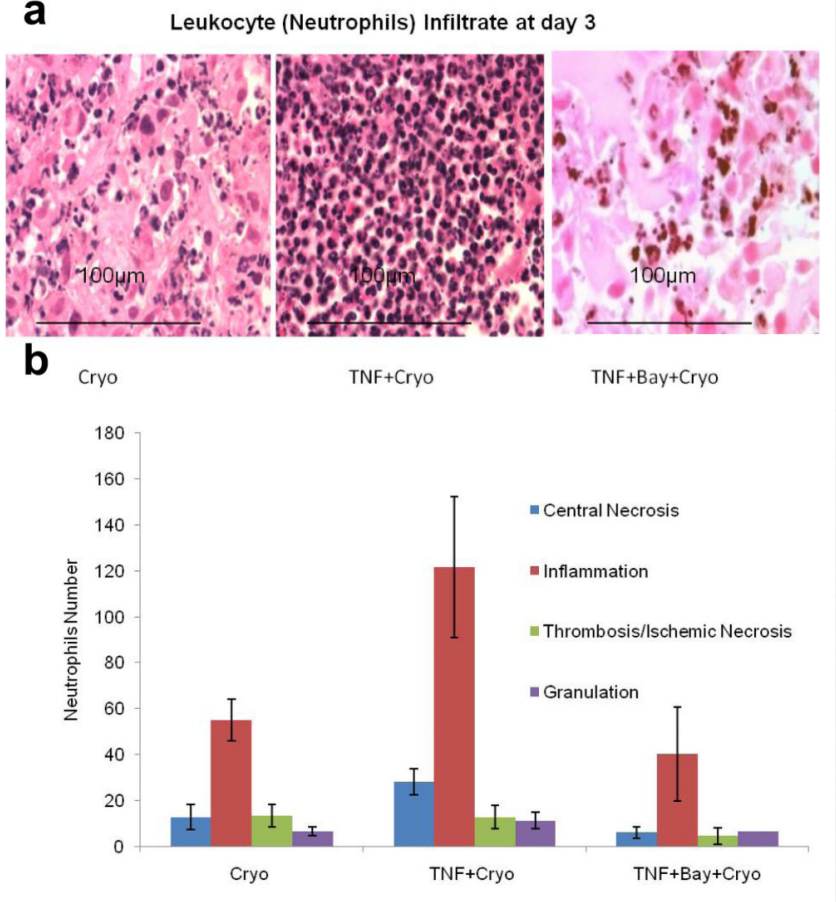

C

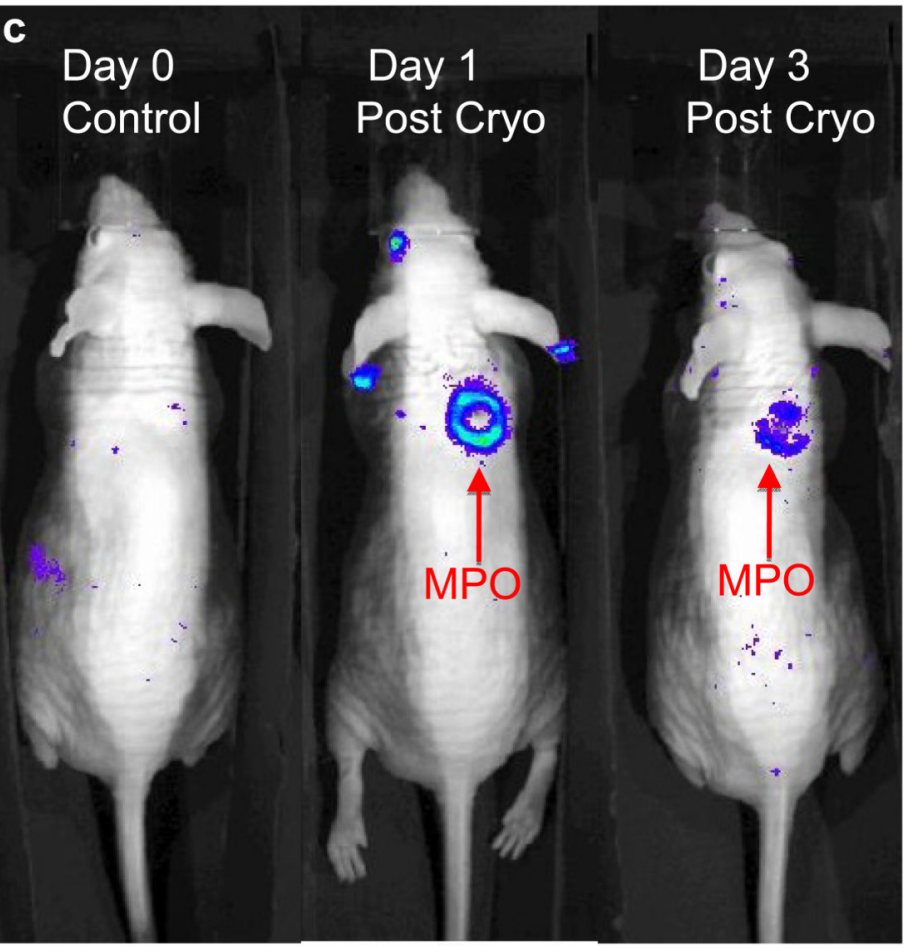

Figure 6. Potential for Non-invasive Imaging of Neutrophil Infiltration into Thermal Lesion (a) Leukocyte (neutrophils) infiltrate at day 3 post cryosurgery with or without TNF- $\alpha$ preconditioning. Animals were treated with cryosurgery alone, TNF- $\alpha 4$ hours pre-conditioning plus cryosurgery, or NFKB inhibitor BAY followed by TNF- $\alpha 4$ hours pre-conditioning plus cryosurgery. Representative image of neutrophilic infiltrate with $\mathrm{H} \& \mathrm{E}$ staining was taken under high power $(100 \times$ magnification) within the inflammation zone (scale bar $=100 \mu \mathrm{m})$. (b) Quantification of neutrophils within each histological zone under high power field. The average number of neutrophils was measured in five representative fields in each histological layer for each sample. The bar values represent mean $\pm \mathrm{SD}$ of three to four independent experiments for each treatment. The numbers of neutrophils per field were significantly different between the combinatorial treatment and cryosurgery alone (*, $\mathrm{p}<0.05$ ) [65]. (c) Luminol bioluminescence imaging of myeloperoxidase (MPO) activity in TRAMP-C2 tumors in vivo following cryosurgery (unpublished results). 
Table 1

\section{Nanoparticles under Clinical Evaluation that Activate or Enhance Thermal Therapy}

\begin{tabular}{|c|c|c|c|c|}
\hline Nanoparticle Class & Examples & Thermal Therapy Application & Company & Indications \\
\hline \multirow[t]{2}{*}{ LIPOSOMAL } & ThermoDox $^{\circledR}$ & $\begin{array}{l}\text { Temperature sensitive liposomes } \\
\text { release doxorubicin within tumors } \\
\text { treated with radiofrequency ablation }\end{array}$ & $\begin{array}{l}\text { Celsion Corporation, New } \\
\text { York, } \\
\text { NY, USA }\end{array}$ & Liver and breast cancer \\
\hline & Myocet $^{\mathrm{TM}}$ & $\begin{array}{l}\text { Liposomally encapsulated doxorubicin } \\
\text { administered as neoadjuvant } \\
\text { chemotherapy with regional } \\
\text { hyperthermia }\end{array}$ & $\begin{array}{l}\text { Sopherion Therapeutics, } \\
\text { Princeton, NJ, USA }\end{array}$ & Metastatic breast cancer \\
\hline \multirow[t]{2}{*}{ METALLIC } & $\begin{array}{l}{ }^{*} \text { Aurimune } \\
(\mathrm{CYT}-6091)\end{array}$ & $\begin{array}{l}\text { Colloidal gold nanoparticle tagged with } \\
\text { TNF preconditions solid tumors to } \\
\text { thermal therapy }\end{array}$ & $\begin{array}{l}\text { CytImmune Sciences, } \\
\text { Rockville, } \\
\text { MD, USA }\end{array}$ & Solid tumors \\
\hline & AuroLase $^{\circledR}$ & $\begin{array}{l}\text { Gold nanoshells passively accumulate } \\
\text { within solid tumors and are activated } \\
\text { by near infrared laser to heat tumors }\end{array}$ & $\begin{array}{l}\text { Nanospectra Biosciences, Inc., } \\
\text { Houston, TX, USA }\end{array}$ & Head and neck cancer \\
\hline MAGNETIC & NanoTherm $^{\circledR}$ & $\begin{array}{l}\text { Iron oxide particles injected directly } \\
\text { into tumors absorb high energy } \\
\text { radiation of external magnetic field to } \\
\text { heat tumors }\end{array}$ & $\begin{array}{l}\text { MagForce Nanotechnologies } \\
\text { AG, Berlin, Germany }\end{array}$ & $\begin{array}{l}\text { Glioblastoma multiforme, } \\
\text { prostate cancer, } \\
\text { esophageal cancer, } \\
\text { pancreatic cancer }\end{array}$ \\
\hline
\end{tabular}


Table 2

Thermal Therapy Devices in Clinical Use for Solid Tumors

Note that AuroLase ${ }^{\mathrm{TM}}$ and Nano-Cancer ${ }^{\circledR}$ are nanoparticle-based technologies.

\begin{tabular}{|c|c|c|c|c|}
\hline Thermal Therapy & Probe & Company & Indications & Web \\
\hline \multirow[t]{5}{*}{ CRYOSURGERY } & SeedNetTM+ & Galil Medical, Yokneam, Israel & $\begin{array}{l}\text { Prostate, Kidney Cancers, } \\
\text { Uterine Fibroids }\end{array}$ & www.galil-medical.com \\
\hline & CryoCare CSTM+ & Endocare, Irvine, CA, USA. & $\begin{array}{l}\text { Prostate, Kidney, Lung and } \\
\text { Liver Cancers }\end{array}$ & www.endocare.com \\
\hline & Visica $2 \mathrm{TM}$ & Sanarus, Pleasanton, CA, USA. & Breast fibroadenomas & www.sanarus.com \\
\hline & Various Systems & BryMill, Ellington, CT, USA. & Dermatologic Lesions & www.brymill.com \\
\hline & Erbokryo CATM & Erbe Medical, Leeds, UK. & General Surgical Use & www.erbe-med.com \\
\hline \multirow[t]{5}{*}{ RADIOFREQUENCY } & $\begin{array}{l}\text { Cool-Tip }{ }^{\circledR} \text { RF Ablation } \\
\text { System }\end{array}$ & Valleylab, Boulder, CO, USA. & Tumor ablation & www.valleylab.com \\
\hline & LeVeen needle electrode & $\begin{array}{l}\text { Boston Scientific Corp., Natick, } \\
\text { MA, } \\
\text { USA. }\end{array}$ & $\begin{array}{l}\text { Liver and soft tissue } \\
\text { ablation }\end{array}$ & www.bostonscientific.com \\
\hline & RITA system & $\begin{array}{l}\text { AngioDynamics, Inc., } \\
\text { Queensbury, } \\
\text { NY, USA. }\end{array}$ & $\begin{array}{l}\text { Surgical oncology, tumor }(\leq \\
7 \\
\mathrm{~cm}) \text { ablation }\end{array}$ & www.angiodynamics.com \\
\hline & HiTT & Berchtold, Tuttlingen, Germany. & Tumor ablation & www.berchtoldusa.com \\
\hline & Prostiva $^{\circledR}$ RF & Medtronic, Inc., MN, USA & Benign prostatic hyperplasia & www.medtronic.com \\
\hline $\begin{array}{l}\text { HIGH INTENSITY } \\
\text { FOCUSED }\end{array}$ & Ablatherm ${ }^{\circledR} \mathrm{HIFU}$ & $\begin{array}{l}\text { EDAP TMS S.A., Vaulx-en- } \\
\text { Velin, } \\
\text { France. }\end{array}$ & $\begin{array}{l}\text { Focused surgery, Prostate } \\
\text { cancer } \\
\text { tumor ablation with imaging }\end{array}$ & www.edap-tms.com \\
\hline \multirow[t]{2}{*}{ ULTRASOUND } & ExAblate $^{\circledR} 2000$ & $\begin{array}{l}\text { InSightec-TxSonics, Dallas, } \\
\text { TX, USA. }\end{array}$ & $\begin{array}{l}\text { Tumor/fibroid ablation with } \\
\text { concurrent MR imaging }\end{array}$ & www.insightec.com \\
\hline & Sonalleve & Philips, Netherlands & $\begin{array}{l}\text { Tumor/fibroid ablation with } \\
\text { concurrent MR imaging }\end{array}$ & www.philips.com \\
\hline \multirow[t]{4}{*}{ MICROWAVE } & Targis $^{\circledR}$ & $\begin{array}{l}\text { Urologix, Inc., Minneapolis, } \\
\text { MN, USA. }\end{array}$ & Benign prostatic hyperplasia & www.urologix.com \\
\hline & Prosatron $^{\circledR}$ & $\begin{array}{l}\text { Urologix, Inc., Minneapolis, } \\
\text { MN, USA. }\end{array}$ & $\begin{array}{l}\text { Benign prostatic hyperplasia } \\
\text { treatment by } \text { TUMT }^{\circledR}\end{array}$ & www.urologix.com \\
\hline & Microwave AZM-250 & Azwell, Inc., Osaka, Japan. & $\begin{array}{l}\text { Liver tumor ablation, Deep } \\
\text { tissue and surface ablation }\end{array}$ & \\
\hline & Prolieve $^{\circledR}$ & $\begin{array}{l}\text { Boston Scientific Corp., Natick, } \\
\text { MA, } \\
\text { USA }\end{array}$ & Benign prostatic hyperplasia & www.prolieve.com \\
\hline \multirow[t]{3}{*}{ LASER } & INDIGO® Laser System & $\begin{array}{l}\text { Indigo Medical, Inc./Johnson \& } \\
\text { Johnson, Cincinnati, Ohio, } \\
\text { USA. }\end{array}$ & Benign prostatic hyperplasia & www.ethiconendo.com \\
\hline & $\begin{array}{l}\text { GreenLight PV Tм Laser } \\
\text { System }\end{array}$ & AMS, Minnetonka, MN, USA. & Benign prostatic hyperplasia & www.greenlighthps.com \\
\hline & AuroLase $^{\circledR}$ & $\begin{array}{l}\text { Nanospectra Biosciences, Inc., } \\
\text { Houston, TX, USA }\end{array}$ & $\begin{array}{l}\text { Refractory head and neck } \\
\text { cancer }\end{array}$ & www.nanospectra.com \\
\hline $\begin{array}{l}\text { MAGNETIC FLUID } \\
\text { HYPERTHERMIA }\end{array}$ & Nano-Cancer $^{\circledR}$ & $\begin{array}{l}\text { MagForce Nanotechnologies } \\
\text { AG, } \\
\text { Berlin, Germany }\end{array}$ & $\begin{array}{l}\text { Glioblastoma multiforme, } \\
\text { prostate cancer, esophageal } \\
\text { cancer, pancreatic cancer }\end{array}$ & www.magforce.de \\
\hline
\end{tabular}


Table 3

\section{Potential Pre-conditioning Agents for Thermal Therapies}

This is not intended as a comprehensive list, but only to highlight the potential of tumor microenvironment targets for pre-conditioning.

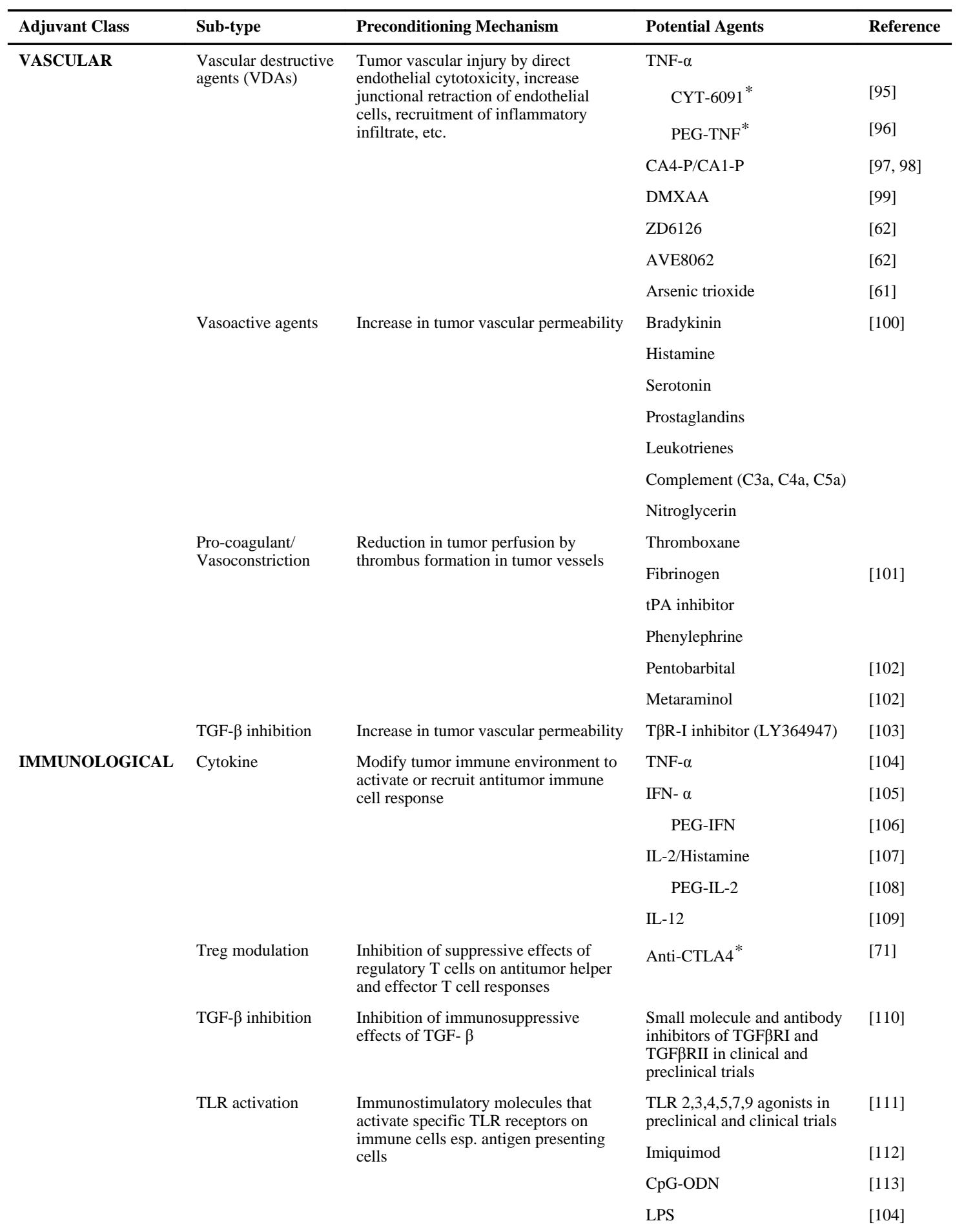




\begin{tabular}{|c|c|c|c|c|}
\hline Adjuvant Class & Sub-type & Preconditioning Mechanism & Potential Agents & Reference \\
\hline & & & BCG-CWS & [114] \\
\hline & & & OK-432 & [115] \\
\hline & & & siRNA-PEI ${ }^{*}$ & [116] \\
\hline & & & Anti-CD40-PLA* & [117] \\
\hline
\end{tabular}


